Article

\title{
Limit Carrying Capacity Calculation of Two-Way Slabs with Three Simply Supported Edges and One Clamped Edge under Fire
}

\author{
Sanfan Zhu ${ }^{1,2}{ }^{\mathbb{D}}$, Yuli Dong ${ }^{1, *}$, Sengui Ye ${ }^{1}$, Dashan Zhang ${ }^{1}$ and Jintao Duan ${ }^{1}$ \\ 1 College of Civil Engineering, Huaqiao University, Xiamen 361021, China; zsf8235566@163.com (S.Z.); \\ yesengui0910@icloud.com (S.Y.); zhangdashan1981@163.com (D.Z.); djtworkaholic@163.com (J.D.) \\ 2 JianYan Test Group Company Limited, Xiamen 361004, China \\ * Correspondence: DongYL@hqu.edu.cn; Tel.: +86-137-9976-9738
}

check for

updates

Citation: Zhu, S.; Dong, Y.; Ye, S.;

Zhang, D.; Duan, J. Limit Carrying Capacity Calculation of Two-Way Slabs with Three Simply Supported Edges and One Clamped Edge under Fire. Appl. Sci. 2022, 12, 1561.

https://doi.org/10.3390/ app12031561

Academic Editors: Jong Wan Hu and Junwon Seo

Received: 6 December 2021

Accepted: 24 January 2022

Published: 31 January 2022

Publisher's Note: MDPI stays neutral with regard to jurisdictional claims in published maps and institutional affiliations.

Copyright: (C) 2022 by the authors. Licensee MDPI, Basel, Switzerland. This article is an open access article distributed under the terms and conditions of the Creative Commons Attribution (CC BY) license (https:// creativecommons.org/licenses/by/ $4.0 /)$.

\begin{abstract}
Fire-resistance experiments were conducted on two full-scale two-way reinforced concrete slabs with three simply supported edges and one clamped edge. This paper presents the design of the furnace, specimens and clamped-end device, the test plan, and the measuring contents and methods. The cracking and failure characteristics of the tested two-way reinforced concrete slabs were introduced. The temperature field distribution of the concrete and steel in the direction of the section thickness, out-of-plane deflections, in-plane deflections, and angle of the slab edges of the two-way concrete slab under fire conditions were analyzed. Cracks form on the slab surface, which is shaped similar to the bottom of a shallow bowl, with two transverse cracks in the mid-area of the medially clamped side and intensively annular diagonal cracks on the corner side. There were several main transverse cracks in the central area of the slab surface. The results indicate that there was a significant decrease in frequency under fire conditions. Relations between the frequency and the central vertical deflection of the two slabs were analyzed by the regression method. This research generates valuable test data that can be used to validate the numerical models developed by fellow researchers in the field of structural fire engineering. Based on the plate balance method and energy method, calculation formula of the limit carrying capacity calculation formula of reinforced concrete two-way slabs with four different boundaries under fire are given, which are simply supported on three sides and clamped on one side. The influence of membrane effect under large deflection is considered in the formula, and the calculated results are in good agreement with the experimental results.
\end{abstract}

Keywords: two-way slab; three simply supported edges and one clamped edge; full-scale test; fire performance; limit bearing capacity; plate balance method; energy method

\section{Introduction}

At room temperature, reinforced concrete slabs will produce both compressive membrane effects and tensile membrane effects, which are related to their supporting conditions. For a concrete two-way slab with four fixed sides, the compressive membrane effect will be produced because of the action of arching caused by the horizontal restraint of the four sides that occurs when the deflection of the slab is less than the thickness of the slab. When the deflection of the plate is larger than the thickness of the slab, the tensile film effect will occur. For other supporting conditions without horizontal restraint, there is no compression membrane effect; when the deflection is larger than the thickness of the plate, the tensile membrane effect will occur. In the case of fire, the deflection of reinforced concrete slabs develops rapidly under the action of high temperature, and the deflection is usually several times the thickness of the slab. At this time, the tensile membrane effect of concrete slab has an important influence on the fire resistance of structure.

During the 1960s, the effects of restraints on concrete floor systems that were exposed to fire were studied by the Portland Cement Association (PCA) [1,2]. In 1990, Vecchio et al. [3] conducted eight full-scale tests on concrete slab to investigate the effect 
of the temperature gradient on the serviceability and ultimate load states of slabs. In 2002 and 2004, Lim et al. [4,5] conducted fire resistance tests on various types of simply supported reinforced concrete two-way slabs and verified that the tensile membrane effect can significantly improve the fire resistance of slabs. In 2007, Bailey et al. [6,7] conducted tests under normal temperature and fire conditions on 48 reinforced concrete slabs with reduced sizes and without horizontal restraint. The results showed that the main failure modes are steel bar fracture and corner concrete crushing. At room temperature, the two types of failure modes are related to the reinforcement ratio; at high temperature, the main failure mode is steel bar fracture. This is because the properties of concrete and steel bars are greatly affected by high temperatures and weaken rapidly.

In 2010, Wang and Dong [8] conducted fire tests on two reinforced concrete rectangular slabs with different boundaries: slabs with four edges simply supported and slabs with four clamped edges. For the simply supported slab, several cracks occurred parallel to the short span; for the fixed slab, yield hinge lines of an elliptic shape appeared on the top surface. In 2011, Dong and Zhu [9] reported the test results for a rectangular concrete slab with two clamped edges and two simply supported edges under fire conditions. Under the action of fire, there was an obvious stress redistribution at the fixed edge, the temperature gradient increased rapidly with time, and the cracks on the top of the plate were semielliptical. In 2013 and 2015, Dong et al. [10-12] reported fire tests in one steel-framed building, and the results indicated that concrete floor slabs at larger deflections played a key role in enhancing the fire resistance of the steel-framed building because of tensile membrane action. In 2016, Wang et al. [13] conducted a series of fire tests, which included four full-scale square slabs under combined uniaxial in-plane and out-of-plane loading, along with vertical restraints at the four corners of the slabs. The results showed that cracks parallel to the in-plane restraint force could be more to come in the uniaxially restrained square slabs. In 2018, Wang et al. [14] investigated the effect of the restraint types, restraint forces, and aspect ratio on the deflection and failure modes of four rectangular slabs (Slabs R1 to R4) and one square slab (Slab S6). Based on test results, the effect of uniaxial or biaxial in-plane restraints on the failure mode should be considered to develop reasonable failure criteria for these slabs. In 2020, Wang et al. [15] conducted fire tests on three continuous slabs: one has fire exerted at the side span only, one has fire exerted at both the side and the mid spans, and the other has fire exerted at all three spans. The furnace temperatures of each span, the temperature of concrete and steel, the slab deflection, the restraint forces at slab corners, and the failure modes were obtained.

At present, many scholars have deduced some calculation methods according to their proposed film effect generation mechanism, but there are some problems such as complex calculation process and too many assumptions $[4-7,16,17]$. The author's research group has also conducted in-depth research in this regard: Dong Yuli $[18,19]$ solved the tensile membrane effect of concrete slab by using the deformation and decomposition principle and gave the calculation formula of the ultimate bearing capacity of rectangular and square two-way slabs without horizontal constraints. On this basis, Yang Zhinian [20], Zhu Chongji [21,22], and Zhang Dashan [23,24] proposed formulas for calculating the ultimate bearing capacity of reinforced concrete two-way slabs under fire, considering the tensile membrane effect with simply supported on four sides, fixedly supported on four sides, simply supported on adjacent sides and fixed supported on adjacent edges, and formulas for calculating the limit load-carrying capacity of two-way slab floors with beams only on columns and one-way slabs with flat beamless floors.

In the numerical simulation of structural fire resistance analysis, the commonly used finite element software includes: ABAQUS [25,26], FEAST [27], SAFIR [28], ADAPTIVE [29], Vulcan [30,31], etc. At present, the work of Vulcan used to analyze the slab is mainly proposed by Huang [30,31]. The reinforced concrete slab is divided into several layers along the thickness direction, and the reinforcement is dispersed into separate reinforcement layers. The element used is a 4-node shell element. The formula used is based on the overall Lagrangian coordinates, and the Newton Raphson iterative method is used to solve 
the equation. Among the above software, FEAST and SAFIR cannot be used to simulate the tensile film effect, and only Vulcan can describe the tensile membrane film effect best. However, due to the Green strain tensor, when the deflection is large, the rotation of the plate along the thickness direction is very obvious, which cannot be described by the overall Lagrangian coordinate and Green strain tensor. Therefore, in the case of large deflection, there will be slow convergence or even non-convergence.

In this paper, experiments were conducted on two full-scale two-way reinforced concrete slabs with three simply supported edges and one clamped edge, which are boundary conditions that have not been tested before. The purpose of the test is to research the temperature field distribution, deflection change at different positions, in-plane displacement change, crack occurrence, and development and failure mechanism of concrete slab under different support conditions. The influence of boundary conditions on the fire resistance of two-way slab is studied to fill the gap of previous research. The research generated valuable test data that can be used to validate the numerical models developed by fellow researchers in the field of structural fire engineering. Based on the original work of the research group, this paper further studies the calculation of the limit load-carrying capacity of reinforced concrete two-way slabs with three simply supported edges and one clamped edge.

\section{Test Overview}

\subsection{Specimen Design}

Two full-scale two-way reinforced concrete slabs (CS1 and CS2) were designed with the same parameters, according to the Code for Design of Concrete Structures of China [32]. The axial dimensions of the specimens were $7150 \mathrm{~mm} \times 5650 \mathrm{~mm}$. The lay length and the sliding of the simply supported edge caused by the vertical deflections of the slab under fire conditions were considered, and the three simply supported edges of the slab were extended $200 \mathrm{~mm}$ along the axis. The location of the clamped edge and reaction trough was considered, and the long-clamped edge was extended $525 \mathrm{~mm}$ outward along the short span direction. The dimensions and steel bars of the specimen are shown in Figure 1 and Table 1.
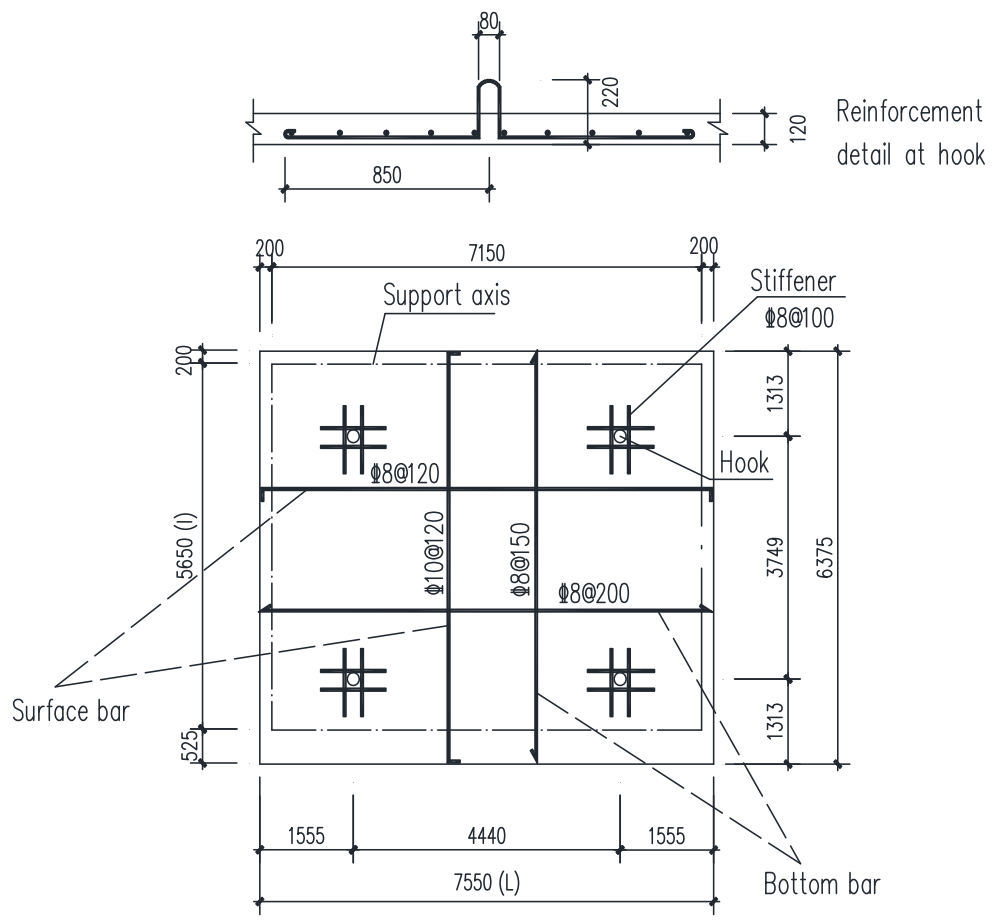

Figure 1. Dimension and steel bar arrangement of the specimen (dimensions in $\mathrm{mm}$ ). 
Table 1. Reinforcement details.

\begin{tabular}{|c|c|c|c|c|c|c|}
\hline Slab & Size (mm) & $\begin{array}{l}\text { Type of } \\
\text { Steel Bar }\end{array}$ & $\begin{array}{l}\text { Bottom } \\
\text { Steel Bar }\end{array}$ & $\begin{array}{c}\text { Top Steel } \\
\text { Bar }\end{array}$ & $\begin{array}{l}\text { Yield } \\
\text { Strength of } \\
\text { Steel Bar }\end{array}$ & $\begin{array}{c}\text { Ultimate Tensile } \\
\text { Strength of Steel } \\
\text { Bar }\end{array}$ \\
\hline CS1/CS2 & $\begin{array}{c}7550 \times 6375 \\
\times 120\end{array}$ & HRB400 & $\begin{array}{c}8 @ 200 \\
\text { (long span) } \\
10 @ 120 \\
\text { (short span) }\end{array}$ & $\begin{array}{c}8 @ 120 \\
\text { (long span) } \\
8 @ 150 \\
\text { (short span) }\end{array}$ & $\begin{array}{c}435 \mathrm{MPa} \\
(\varnothing 8 \mathrm{~mm}) \\
440 \mathrm{MPa} \\
(\varnothing 10 \mathrm{~mm})\end{array}$ & $\begin{array}{c}633 \mathrm{MPa} \\
(\varnothing 8 \mathrm{~mm}) \\
665 \mathrm{MPa} \\
(\varnothing 10 \mathrm{~mm})\end{array}$ \\
\hline
\end{tabular}

The specimens were cast with C30 commercial concrete. The age of concrete at the time of testing was 210 days and 270 days. The compressive strength of the standard concrete cubes cured under the same conditions as the specimens was greater than $30 \mathrm{MPa}$, and the concrete moisture contents of the two specimens were $3.68 \%$ and $3.86 \%$, respectively.

\subsection{Fire Test Furnace}

As shown in Figure 2, the steel frame was set outside the fire furnace body as vertical support, and its size was $7150 \times 5650 \mathrm{~mm}$. The net dimensions of the furnace were $6000 \times 4200 \times 1700 \mathrm{~mm}$, and the inner side of the furnace bottom was equipped with a flue along the length direction, with a width of approximately $470 \mathrm{~mm}$. There were ignition nozzles around the furnace, with five along the long side and two along the short side.
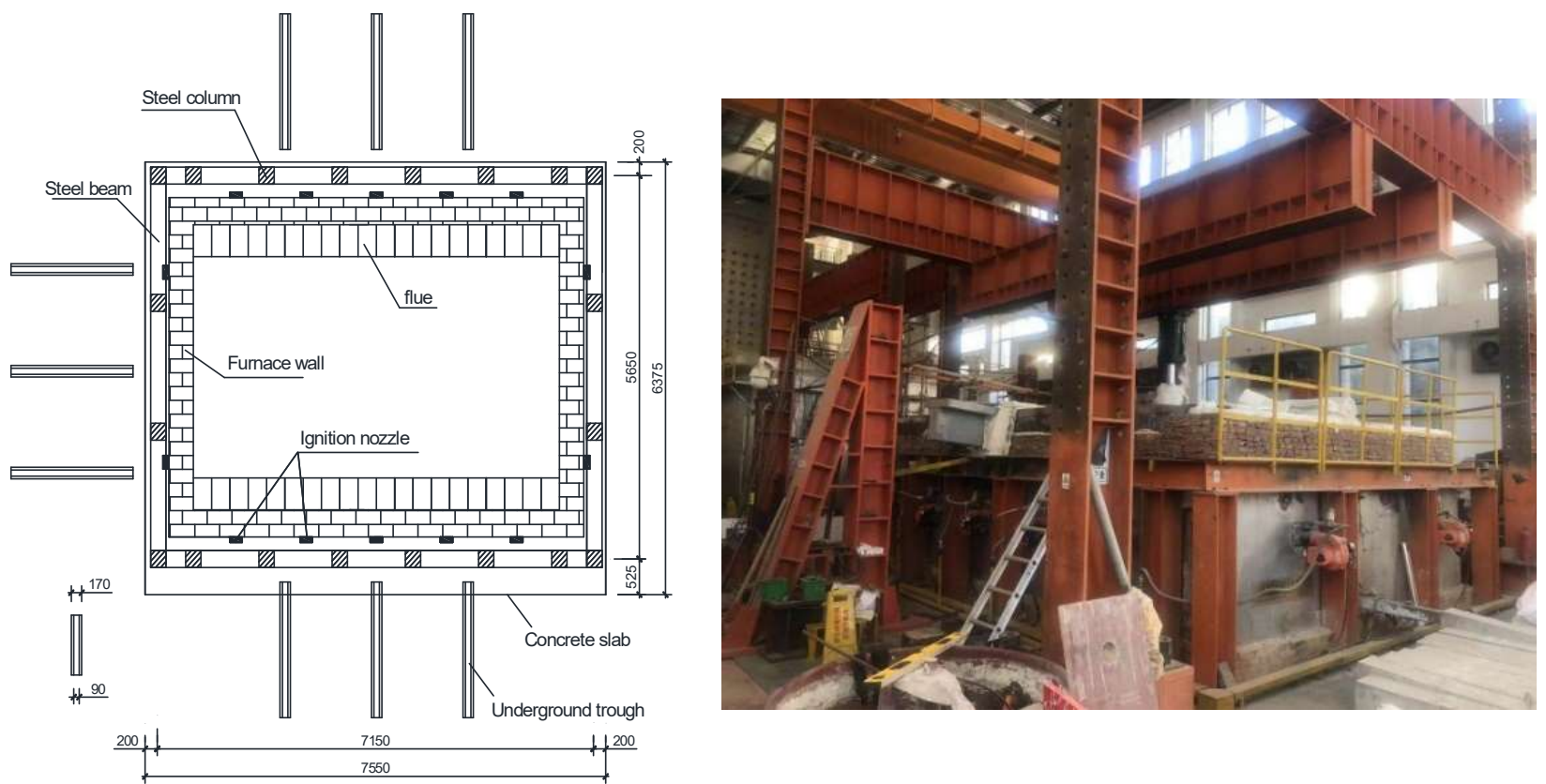

Figure 2. Plan view of the furnace arrangement (dimensions in $\mathrm{mm}$ ).

\subsection{Design of the Support and Restraint Reaction}

Based on the standard for test methods of concrete structures in China [33], the simply supported bearing consisted of four parts: a top slab, bottom slab, roller shaft, and clamped steel bar. The roller shaft was made of cylindrical steel $50 \mathrm{~mm}$ in diameter, and the clamped steel bar was made of plain round steel $16 \mathrm{~mm}$ in diameter. The clamped end of the test was composed of a reaction trough around the furnace body, a reaction beam of homemade steel members, a distribution beam, and a hydraulic jack, as shown in Figure 3. Two high-strength dowel bars with a length of $3.3 \mathrm{~m}$ and diameter of $60 \mathrm{~mm}$ were sufficient to ensure their strength and rigidity in the test. The reaction beam was a box beam $6000 \mathrm{~mm}$ long by $200 \mathrm{~mm}$ wide and $300 \mathrm{~mm}$ high, and the thickness was $20 \mathrm{~mm}$. The position of the reaction trough around the furnace body was not ideal. Two steel boxes were used as the extension conversion of the trough, with dimensions of $650 \times 200 \times 300 \mathrm{~mm}$ and a 
thickness of $20 \mathrm{~mm}$. They were clamped to the trough by two high-strength lead screws with a length of $800 \mathrm{~mm}$ and a diameter of $60 \mathrm{~mm}$, as shown in Figures 3 and 4 . In this experiment, four digital display hydraulic jacks were used to exert restraint reaction forces, and octagonal point loading was realized through a rigid distribution box girder. In the experiment, the restraint force was controlled by the personnel beside the digital display jack, the indication was read out through the digital display meter, and the hydraulic pressure was adjusted to ensure that the restraint moment at the clamped support end remained unchanged.

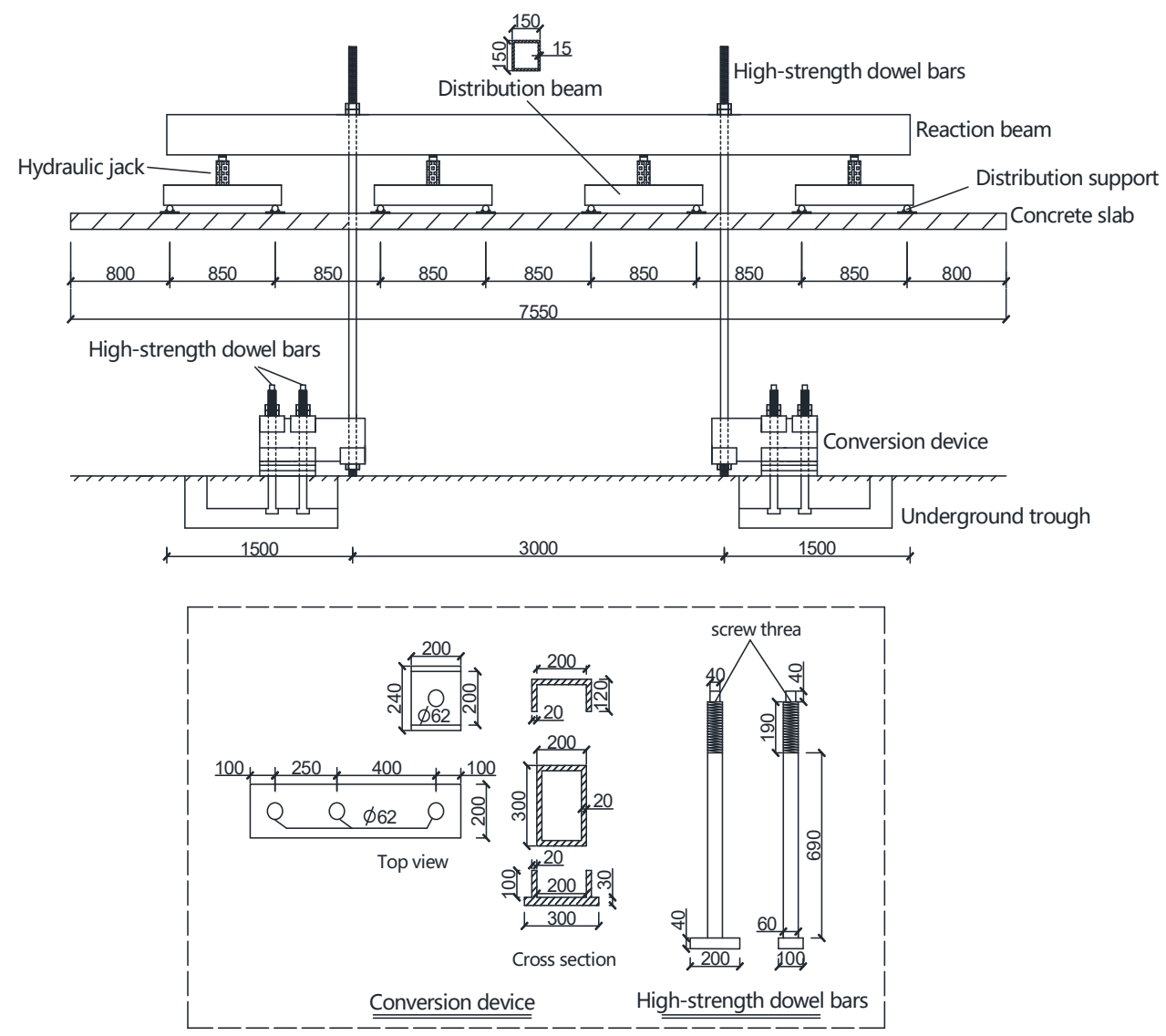

Figure 3. Clamped-end device and loading apparatus for the clamped edge (dimensions in $\mathrm{mm}$ ).

\subsection{Test Loading}

According to the Standard of Load Code for the Design of Building Structures of China [34], the scheme was formulated to simulate the office live load. Iron bricks $(20 \mathrm{~kg})$ were used to simulate a uniformly distributed load $\left(2.0 \mathrm{kN} / \mathrm{m}^{2}\right)$ on the top of the slab, which was equally divided into four levels $\left(0.5 \mathrm{kN} / \mathrm{m}^{2}\right.$ per level). The load of each stage was stable for ten minutes after loading. The fire test start in $30 \mathrm{~min}$ after all loads were applied.

\subsection{Deflections and Slab Edge Angle Measurement}

The out-of-plane deflections of the slabs were measured by a linear variable differential transformer (LVDT), the in-plane horizontal deflections were measured by bridge displacement transducers, and the slab edge angle was measured by a clinometer. The arrangement of the deflections and tilt transducers is shown in Figure 5, and the LVDT data were collected by the Isolated Measurement Pods (IMP). 


\subsection{Temperature Measurement}

The arrangement of the thermocouple measuring points is shown in Figure 5. Nine groups of thermocouple trees were arranged, and each thermocouple trees consisted of seven K-type thermocouples. The first thermocouple was located at the bottom of the slab, the seventh thermocouple was located at the top of the slab, and the remaining thermocouples were evenly arranged with a spacing of $20 \mathrm{~mm}$. The temperature of the steel bar was measured by a K-type thermocouple that was directly connected to the bottom and top steel bars at each measuring point.

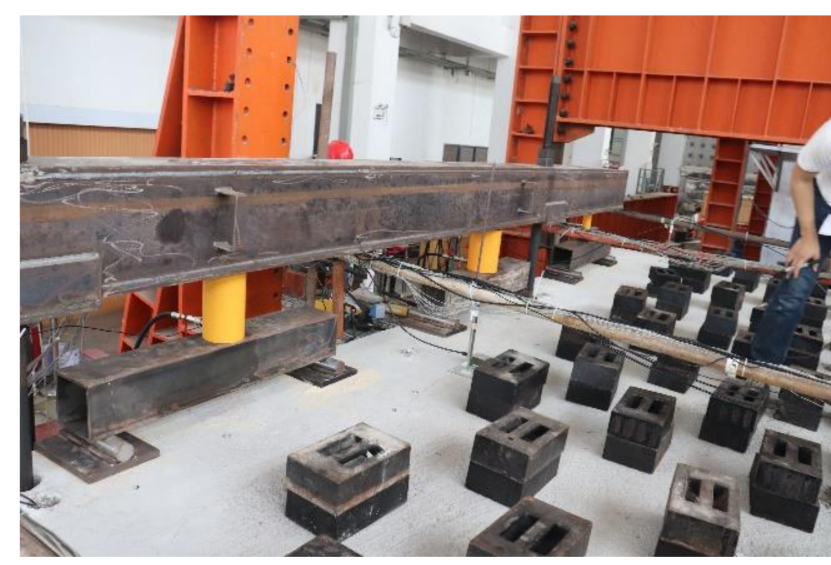

(a)

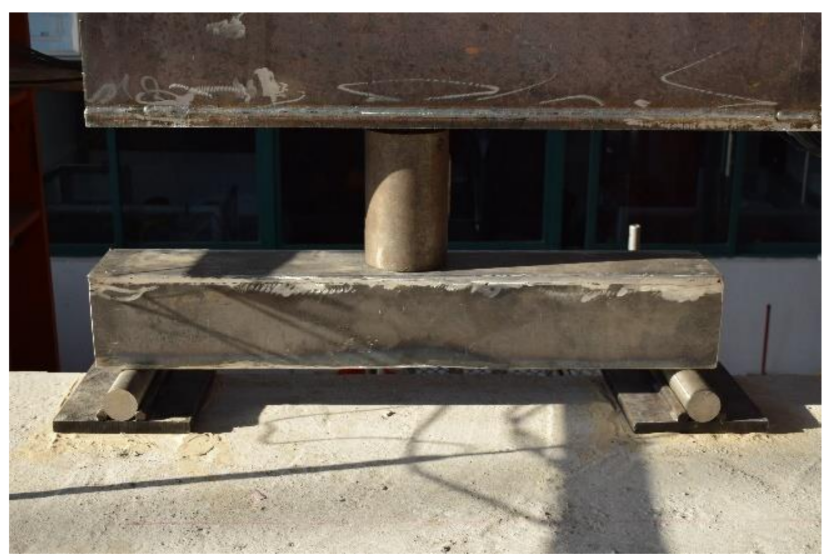

(b)

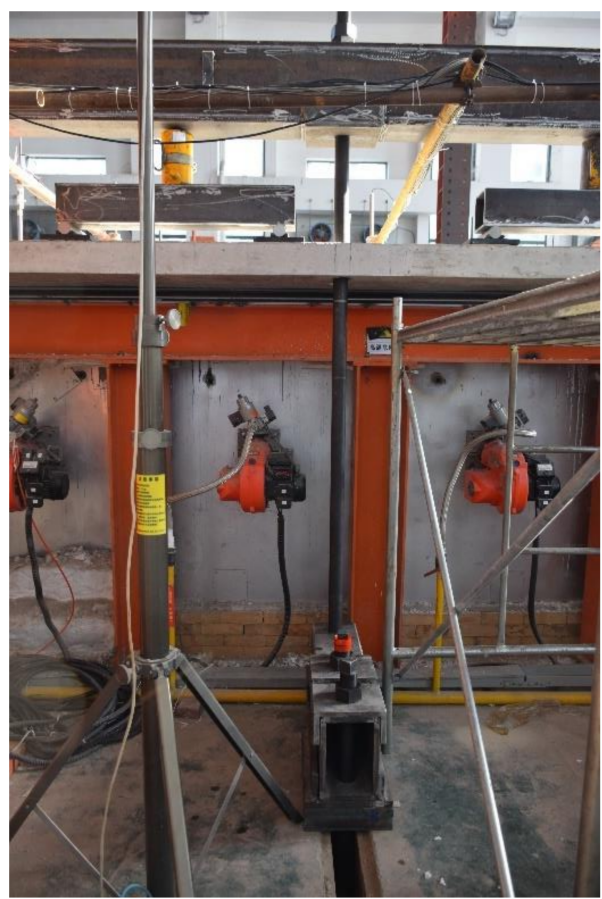

(c)

Figure 4. Photograph of the clamped-end device and conversion device: (a) clamped-end device, (b) distribution support, and (c) conversion device. 


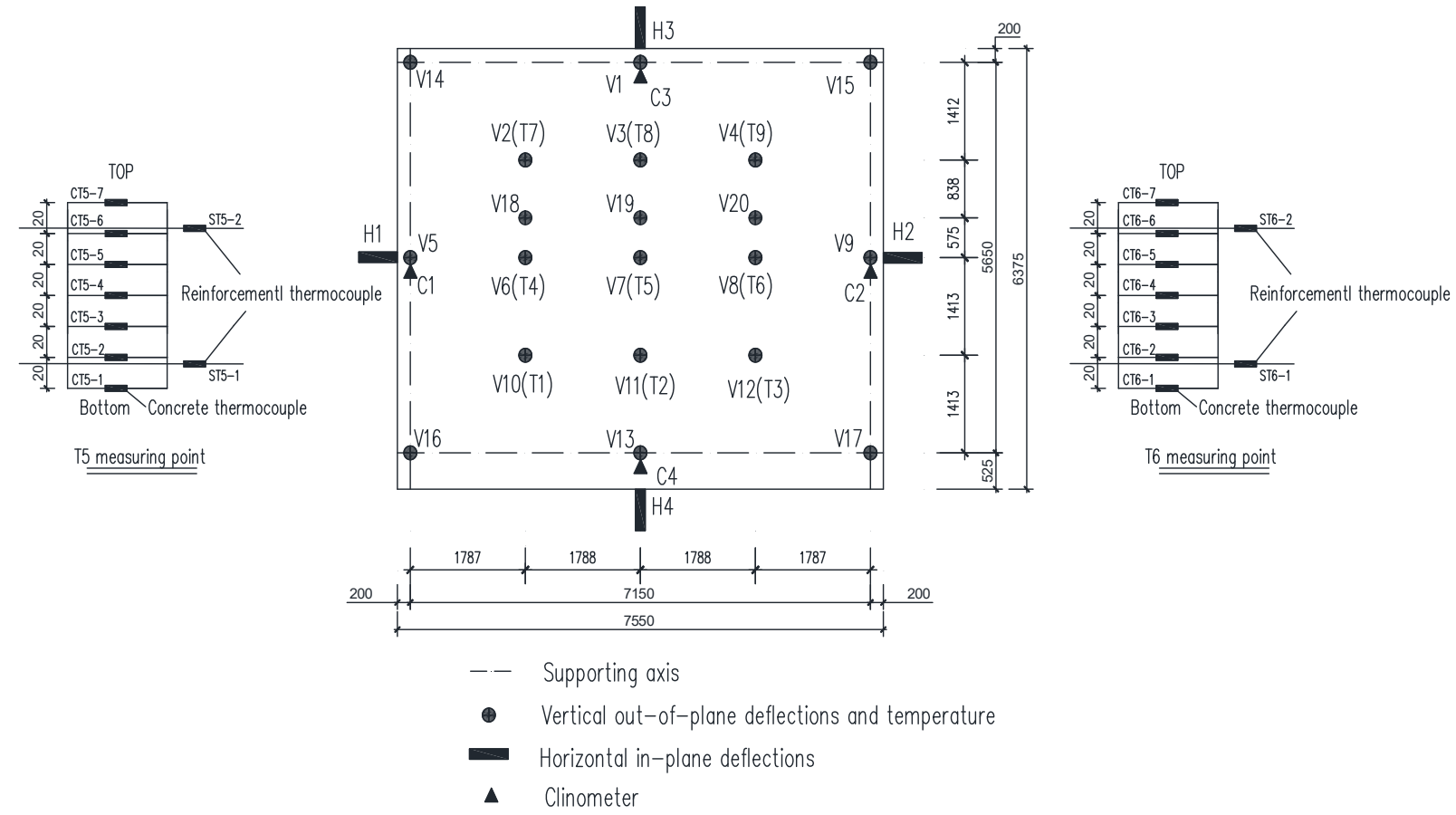

Figure 5. Arrangement of the deflections and tilt transducers (dimensions in $\mathrm{mm}$ ).

\section{Experimental Results}

\subsection{Macroscopic Phenomena and Failure Characteristics}

The macroscopic phenomena and failure characteristics of the two specimens were similar. At the beginning of the test, slab angles $C$ and $D$ begin to tilt slightly. After approximately 5 min, crack (1) developed along the axis of clamped edge $A B$, as shown in Figure 6a. At $13 \mathrm{~min}$, the warpage of slab angles $C$ and D increased continuously (as shown in Figure $6 \mathrm{~b}$ ), cracks (2) and (3) inclined at L/4 L/2 from the clamped edge at approximately $45^{\circ}$ to the simply supported edge that appeared near slab angles $\mathrm{A}$ and $\mathrm{B}$, and main cracks (4) parallel to the short span direction and from the middle to the supporting axes on both sides appeared in mid-span. After the concrete cracks at the axis of the clamped support side, the negative bending moment of the inner plate of the axis increases, and crack (5) (as shown in Figure 6c) appears $160 \mathrm{~mm}$ away from the axis of the clamped support side after $18 \mathrm{~min}$. Several cracks along the short span direction (such as cracks (6) and (7), as shown in Figure 6d) appear on both sides of main crack (4). At approximately $21 \mathrm{~min}$, there is a depression in the center of the plate, arc diagonal cracks increase near corners A and B of the clamped side slab, and diagonal cracks (8) appear. At $30 \mathrm{~min}$, the vertical cracks on the side of each slab increase (as shown in Figure 6e), and the axial direction of both sides appears in turn. The test is stopped at $180 \mathrm{~min}$ for slab CS1 and $210 \mathrm{~min}$ for slab CS2. Four hours after the test, the width of the cracks on the surface of the slabs were reduced compared with the experimental results. The middle part of the board was depressed, and the four corners of the board rebound. The cracking form of the top crack of the two slabs is shown in Figure 7, and the failure mode that resembles the bottom of a shallow bowl is finally formed.

During the heating stage, water stains began to appear at the cracks on the top of the slab at approximately $18 \mathrm{~min}$; at approximately $26 \mathrm{~min}$, the rate of water increase at the top of the slab was obviously fast, and water evaporation began to appear at the crack along the thickness of the slab. At approximately $71 \mathrm{~min}$, the water that accumulated in the concave part of the slab surface reached the maximum, accompanied by a large amount of water evaporation (as shown in Figure 6f); at approximately $140 \mathrm{~min}$, the puddles on the top of the slab began to decrease. 

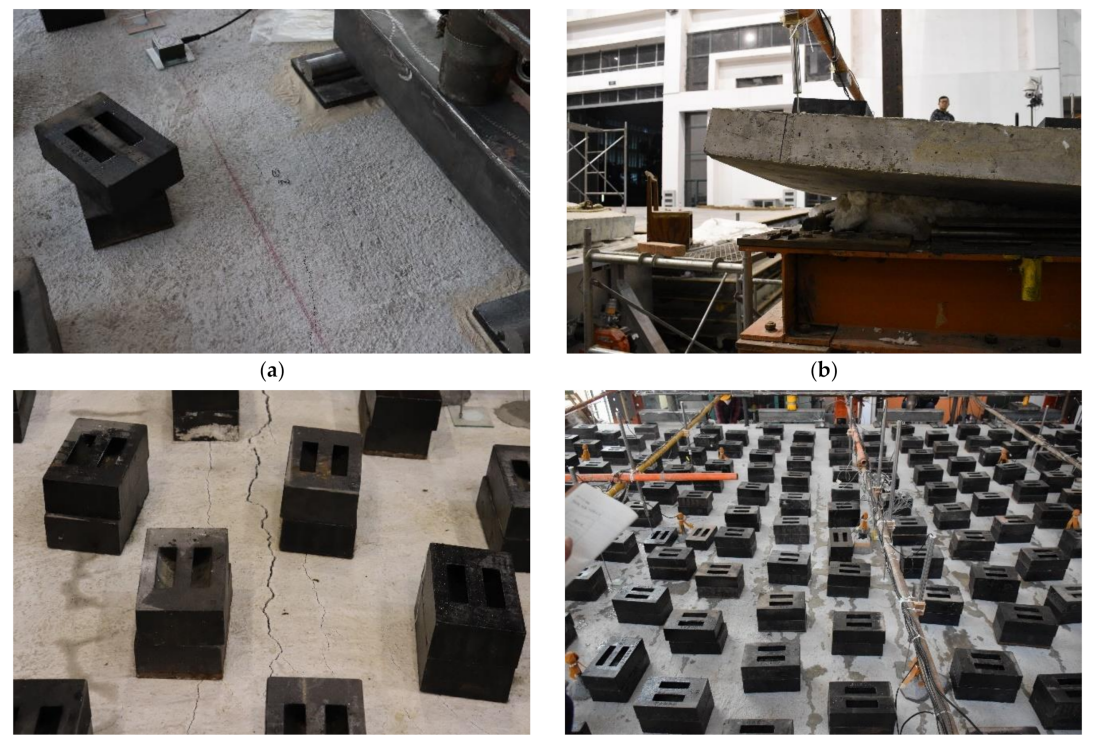

(c)

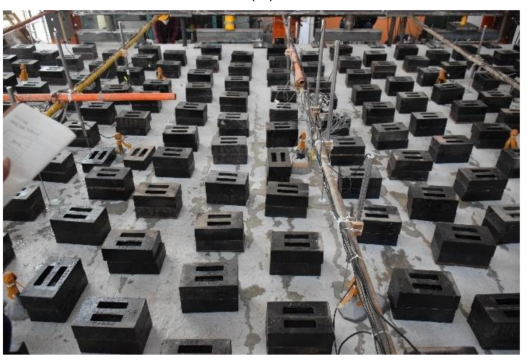

(d)
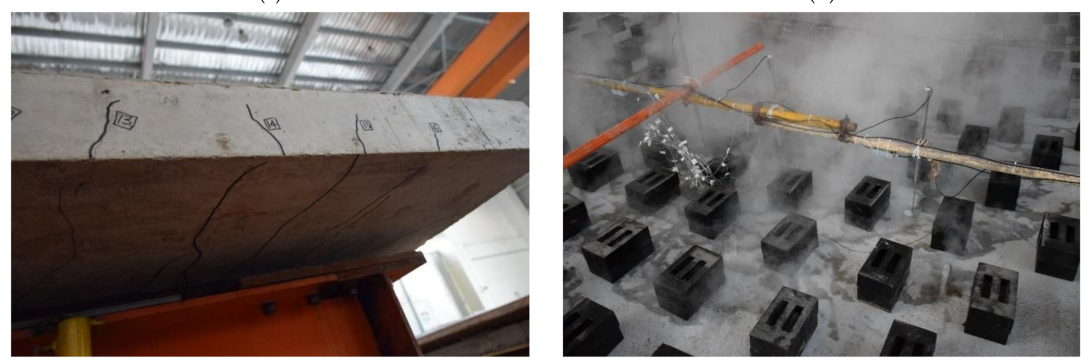

(e)

(f)

Figure 6. Macroscopic phenomenon of the slab surface: (a) crack developed along the axis of clamped edge, (b) tilt of the slab angle, (c) cracks along the short span direction, (d) cracks along the short span direction, (e) cracks on the side of the slab and (f) surface water vapor.

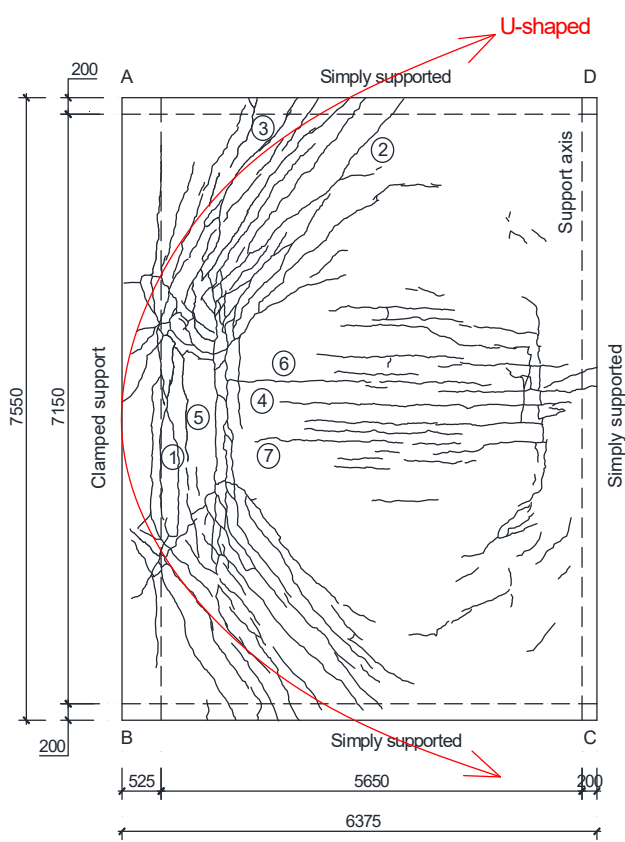

(a)

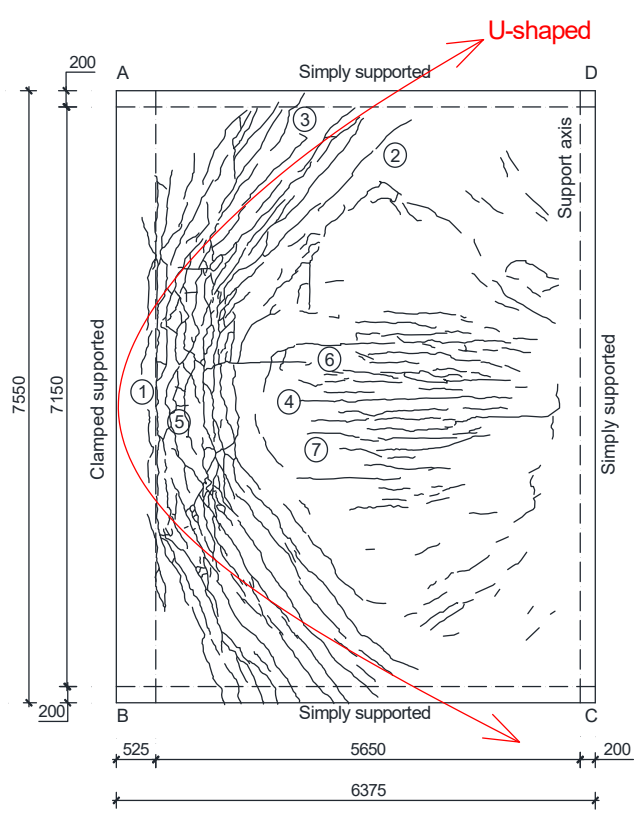

(b)

Figure 7. Cracking development during the test (top surface of slab, dimensions in mm). (a) Slab CS1. (b) Slab CS2. 
When the temperature inside the furnace rises, due to the action of fixed end bending moment, the negative bending moment at the fixed support axis is large. When the ultimate tensile strength of concrete is less than its value, the concrete will crack first. As the temperature rises, the concrete strength decreases sharply. The bending moment in the middle of the slab span is related to the length of the slab span. The bending moment in the middle of the long span of the concrete slab is large, and the concrete in the slab is compressed and cracked along the short span direction, resulting in cracks. Due to the temperature rise, the concrete slab expands, the slab angle is warped, the slab angle force is upward, and the slab surface is subjected to downward uniformly distributed load. Under the coupling of temperature and load, oblique annular cracks are produced in the corner of the plate. When the concrete in the area of the fixed support axis is cracked, the redistribution of the internal force of the slab is obvious, the fixed support effect on the outside of the fixed support axis is reduced, and the negative bending moment on the inside is gradually increased. At the same time, the slab surface is cracked along the long span direction due to the warpage of the slab angle. In the fire area at the bottom of the slab, most of the small chaps appear on the surface of the slab bottom due to the influence of temperature, and there are no regular cracks. The radial cracks in the non-fire area are caused by the large difference between the concrete temperature in the non-fire area and the fire area and the different expansion degree of the concrete.

As shown in Figure 8, the fire affected area at the bottom of the slab is grayish white, and the unfired area is grey. There is an obvious dividing line between the two areas, accompanied by remarkable explosive spalling phenomenon. The main feature of explosive spalling is the burst-out of concrete pieces accompanied by the sudden release of energy and loud sounds [35]. Numerous factors affect the explosive spalling of concrete, while a thorough commentary on each one of them can be found in the literature [35-39]. Affected by high temperature, the fire area of the bottom of the slab was mostly damaged by fire, and there is no regular crack. The radial cracks in the unfired area (as shown in Figure 9) were caused by the large difference in concrete temperature between the unfired area and the fire area and the different expansion degrees of concrete.

Compared with the characteristics of other boundary conditions, the macroscopic phenomena and failure characteristics of the two-way slab with a coaxial line as the boundary condition after fire exposure are analyzed, and their similarities and differences are shown in Table 2. It can be seen from the comparison that the boundary condition is the decisive factor affecting the fire failure characteristics of two-way slabs. The temperature rise leads to the concrete expansion of the concrete slab, the constraint effect of the fixed support is large, the simple support has no constraint, and all the cracks on the two-way slab surface with different boundaries are concentrated on the fixed support side.

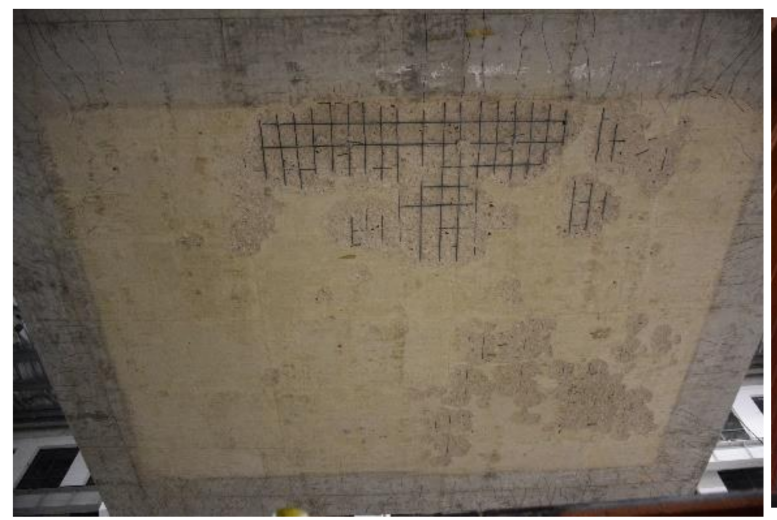

(a)

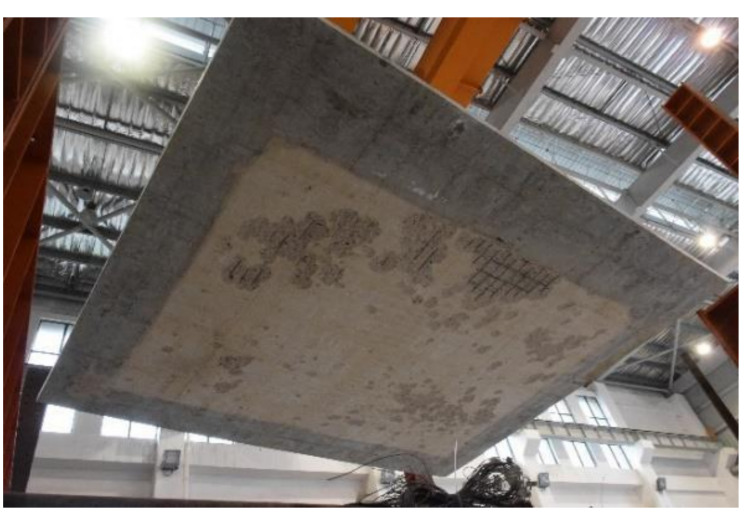

(b)

Figure 8. Macroscopic phenomenon of the bottom of the slab. (a) Slab CS1. (b) Slab CS2. 


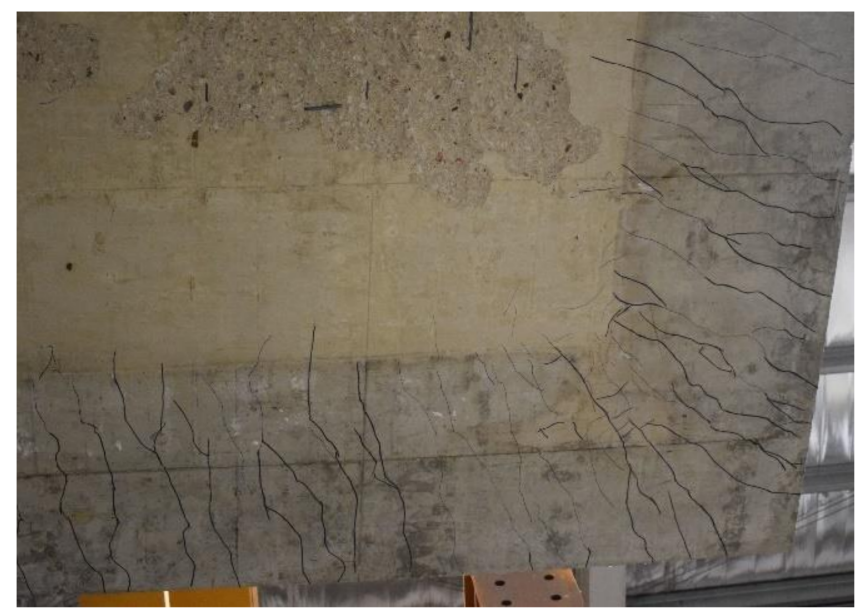

Figure 9. Crack diagram of the unfired area at the bottom of the slab (slab CS1).

The explosive spalling duration at the bottom of the slab lasts a long time (approximately 40-50 $\mathrm{min}$ ), and the explosive spalling phenomenon is obvious. From the bottom of the observation slab, it is evident that half of the area of the center $A B$ for the clamped support edge in the fire area is the main explosive spalling area, and the bottom reinforcement was exposed, but no fracture phenomenon was observed, as shown in Figure 10.

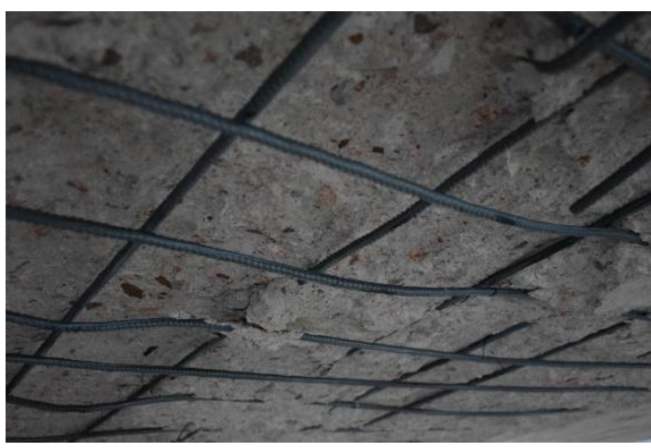

(a)

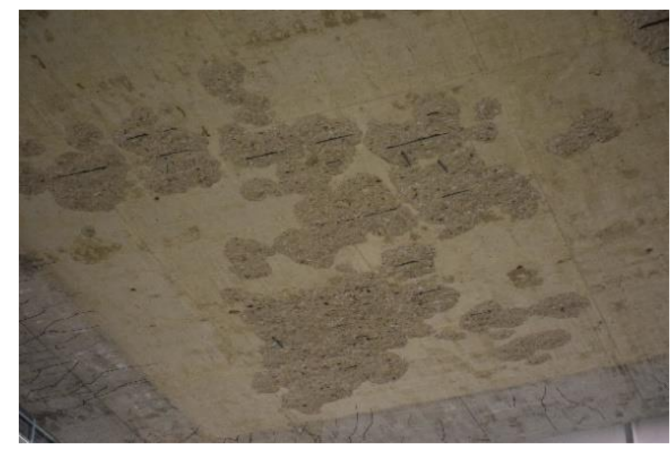

(b)

Figure 10. Bursting diagram of the bottom of the slab. (a) Main explosive spalling zone at the bottom of the slab. (b) Secondary explosive spalling zone at the bottom of the slab.

\subsection{Analysis of the Test Results}

\subsubsection{Test Furnace Temperature}

The temperature rise curve of the test is shown in Figure 11, and the actual temperature rise curve was basically consistent with that of the ISO 834 standard [43]. When the furnace was shut off, the furnace temperatures of slabs CS1 and CS2 were $1106.4{ }^{\circ} \mathrm{C}$ and $1132.0^{\circ} \mathrm{C}$, respectively.

\subsubsection{Section Concrete Temperature}

Figure 12 shows the temperature-time curves of T5. In the initial stage of fire, the temperature of the concrete slab along the section thickness increases in turn, and the temperature inside the concrete reaches $100{ }^{\circ} \mathrm{C}$. In addition to the temperature at the bottom of the slab, there are different gentle stages in turn, and the duration increases in turn. This is because when the concrete slab is exposed to fire, the crystal water inside the slab migrates from the high temperature to the low temperature, and part of the crystal water turns into water vapor by evaporation, which absorbs heat and keeps the temperature of the concrete slab in a relatively balanced state; when the bottom of the slab is in direct contact with the fire, the crystal water can quickly migrate and evaporate, and it will not 
appear in the gentle stage. In the cooling stage, the temperature near the bottom of the slab decreases rapidly, and the temperature at other positions of the vertical section gradually begins to decrease after increasing to different degrees. According to the concrete slab temperature failure criterion for insulation $[4,44]$, when the surface temperature exceeds $180{ }^{\circ} \mathrm{C}$, the standard fire resistance of the two slabs can be determined as shown in Table 3 .

Table 2. Macroscopic phenomena and failure characteristics of two-way slabs after fire under four different conditions.

\begin{tabular}{|c|c|c|c|c|c|}
\hline \multirow[b]{2}{*}{$\begin{array}{c}\text { Boundary Type } \\
\text { and Specimen Size }\end{array}$} & \multicolumn{4}{|c|}{ Top Surface of Slab } & \multirow{2}{*}{$\begin{array}{c}\text { Bottom } \\
\text { Surface of Slab }\end{array}$} \\
\hline & $\begin{array}{l}\text { Overall Shape of } \\
\text { Slab Crack }\end{array}$ & $\begin{array}{l}\text { Cracks Around the } \\
\text { Slab }\end{array}$ & $\begin{array}{l}\text { Cracks in the } \\
\text { Middle of the Slab }\end{array}$ & $\begin{array}{l}\text { Slab } \\
\text { Corners }\end{array}$ & \\
\hline $\begin{array}{l}\text { Three simply supported } \\
\text { edges and one clamped } \\
\text { edge [40], } \\
7550 \times 6375 \times 120 \mathrm{~mm} \text {. }\end{array}$ & $\begin{array}{l}\text { U-shaped (the } \\
\text { opening was the } \\
\text { simply supported } \\
\text { edge corresponding } \\
\text { to the fixed support). }\end{array}$ & \multirow{4}{*}{$\begin{array}{l}\text { (1) Slab was } \\
\text { composed of several } \\
\text { cracks in the middle } \\
\text { of the clamped edge } \\
\text { and dense annular } \\
\text { inclined cracks at the } \\
\text { corners of the } \\
\text { clamped edge. } \\
\text { (2) Slab surface was } \\
\text { depressed downward } \\
\text { to form a basin. }\end{array}$} & \multirow{3}{*}{$\begin{array}{l}\text { Several transverse } \\
\text { main cracks along the } \\
\text { short span direction } \\
\text { in the middle of slab. }\end{array}$} & \multirow{4}{*}{$\begin{array}{l}\text { Corners of the slab } \\
\text { were warped. }\end{array}$} & \multirow{4}{*}{$\begin{array}{l}\text { (1) Radial cracks } \\
\text { were observed in } \\
\text { the area without } \\
\text { fire at the bottom of } \\
\text { the slab. } \\
\text { (2) Several areas at } \\
\text { the bottom of the } \\
\text { slab explosive } \\
\text { spalling severely, } \\
\text { and the } \\
\text { reinforcement was } \\
\text { exposed. }\end{array}$} \\
\hline $\begin{array}{l}\text { Three edges clamped and } \\
\text { one short edge simply } \\
\text { supported [41], } \\
7550 \times 6700 \times 120 \mathrm{~mm} \\
7550 \times 6700 \times 120 \mathrm{~mm} .\end{array}$ & Ellipse. & & & & \\
\hline $\begin{array}{l}\text { Two long edges clamped, } \\
\text { and two short sides } \\
\text { simply supported, } \\
7875 \times 6700 \times 120 \mathrm{~mm} \text {. }\end{array}$ & $\begin{array}{l}\text { U-shaped (the } \\
\text { opening was the } \\
\text { simply supported } \\
\text { edge). }\end{array}$ & & & & \\
\hline $\begin{array}{l}\text { Two short edges clamped, } \\
\text { and two long sides } \\
\text { simply supported [42], } \\
8200 \times 6050 \times 120 \mathrm{~mm} \text {. }\end{array}$ & Ellipse. & & $\begin{array}{l}\text { Many large cracks in } \\
\text { the slab along the } \\
\text { direction of the long } \\
\text { span and short spans. }\end{array}$ & & \\
\hline
\end{tabular}

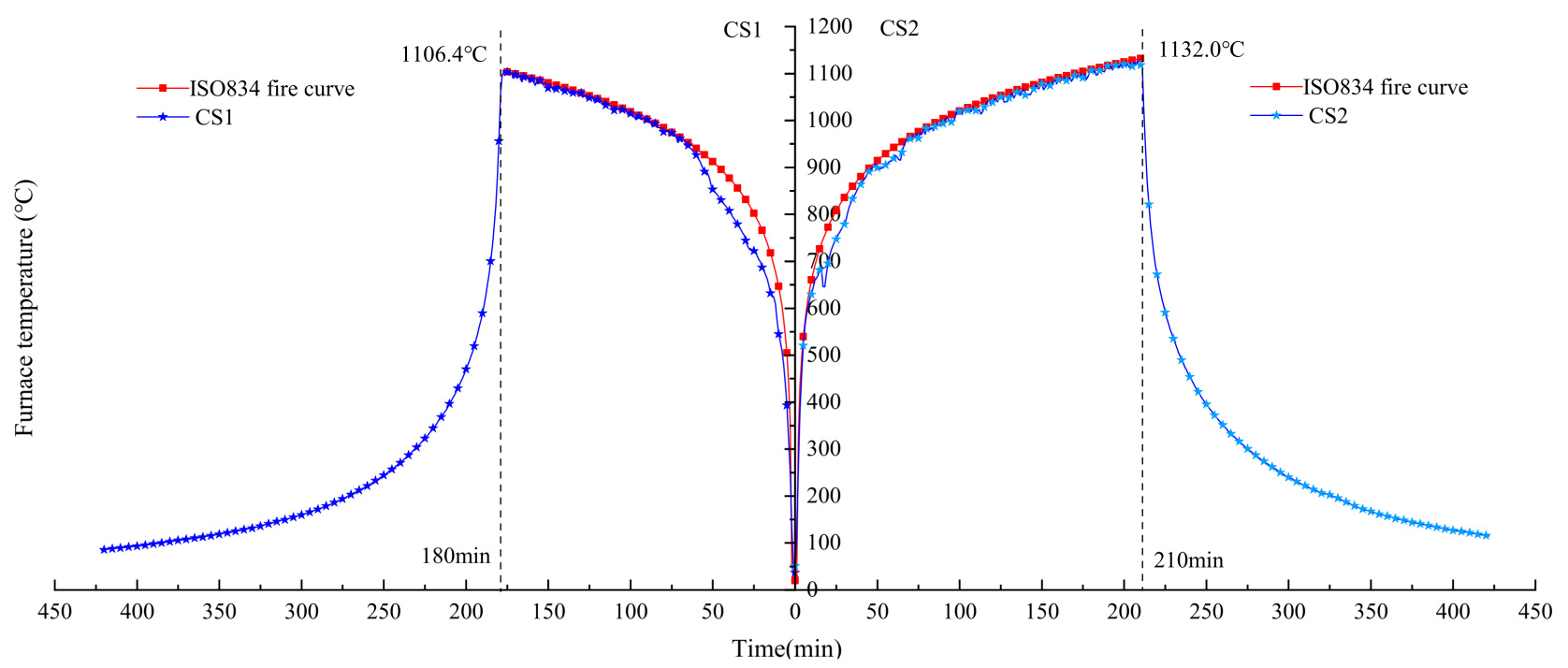

Figure 11. Temperature-time curves of the furnace.

The temperature curve across the full depth with time during the heating stage is shown in Figure 13. According to the test results, the maximum temperatures of CS1 and CS2 at bottom of the slab were $858.2^{\circ} \mathrm{C}$ and $959.2^{\circ} \mathrm{C}$, and the maximum temperatures of the top concrete of the slab were $98.7^{\circ} \mathrm{C}$ and $94.0^{\circ} \mathrm{C}$, respectively. Due to the influence of moisture, the temperature of the concrete at other heights, except for the bottom of the slab, appears to be in an obvious gentle stage at $100^{\circ} \mathrm{C}$. 


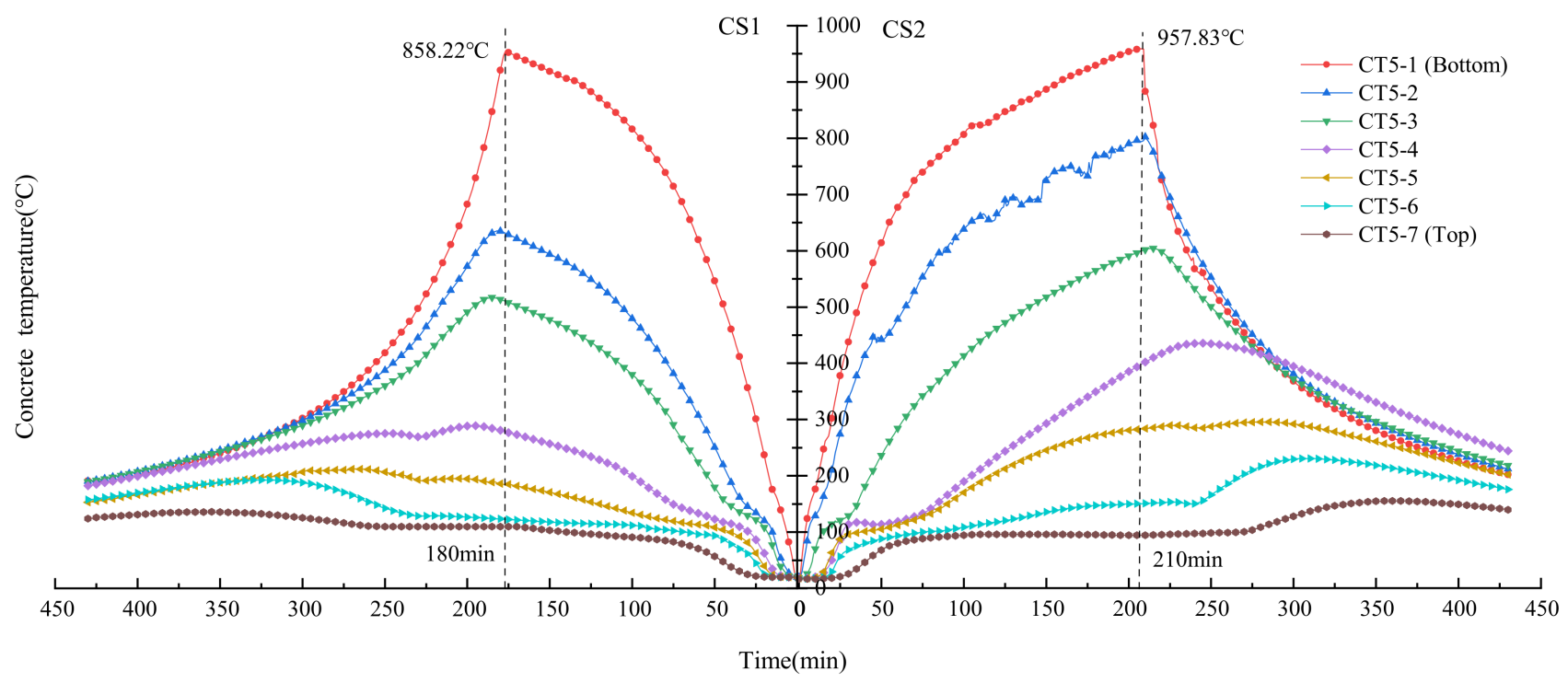

Figure 12. Temperature-time curves of $\mathrm{T} 5$.

Table 3. Fire resistance of the concrete slabs based on different failure criteria (min).

\begin{tabular}{|c|c|c|}
\hline Control Index Slab & CS1 & CS2 \\
\hline Steel temperature & 122 & 160 \\
\hline Concrete temperature & 244 & 210 \\
\hline Deflection (span/30) & 71 & 53 \\
\hline Deflection (span/20) & No failure & No failure \\
\hline Heating time & 180 & 210 \\
\hline
\end{tabular}

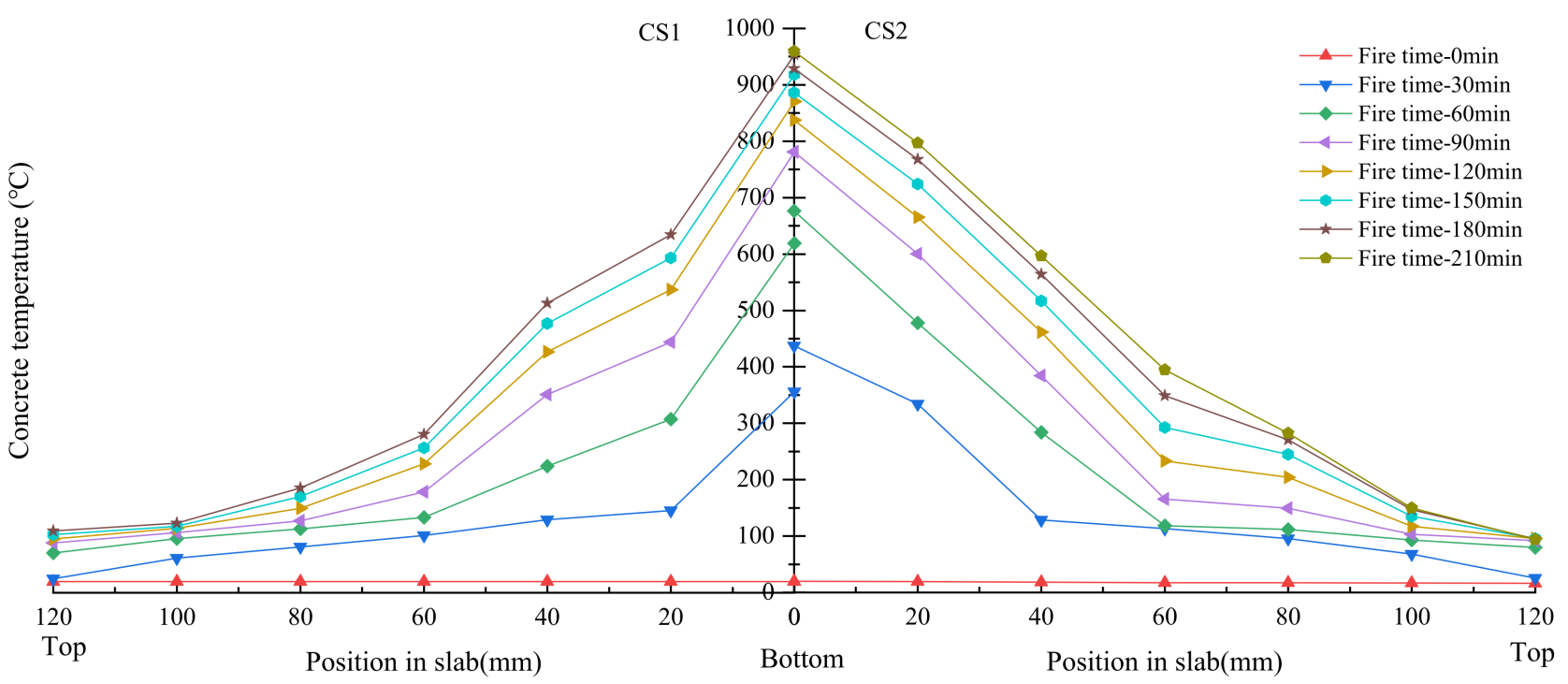

Figure 13. Temperature-time curves across the full height of each slab at T5.

The temperature curve across the full depth, with time, during the cooling stage is shown in Figure 14. In the cooling stage, the temperature gradient gradually slowed down compared with that of the heating stage, and part of the curve was convex. This phenomenon was due to the heat conduction from the bottom concrete to the furnace and the upper concrete, and the temperature decreased rapidly. The middle concrete was only affected by the heat conduction between the interior of the slab, and the decreasing speed was slow; the decreasing speed of the temperature for the upper concrete was between the 
two temperatures under the influence of external air convection and the thermal inertia of the concrete. Due to the different temperature reduction rates of the three parts, the temperature in the middle part was higher than that on both sides, and the stress due to the internal temperature stress of the concrete changed.

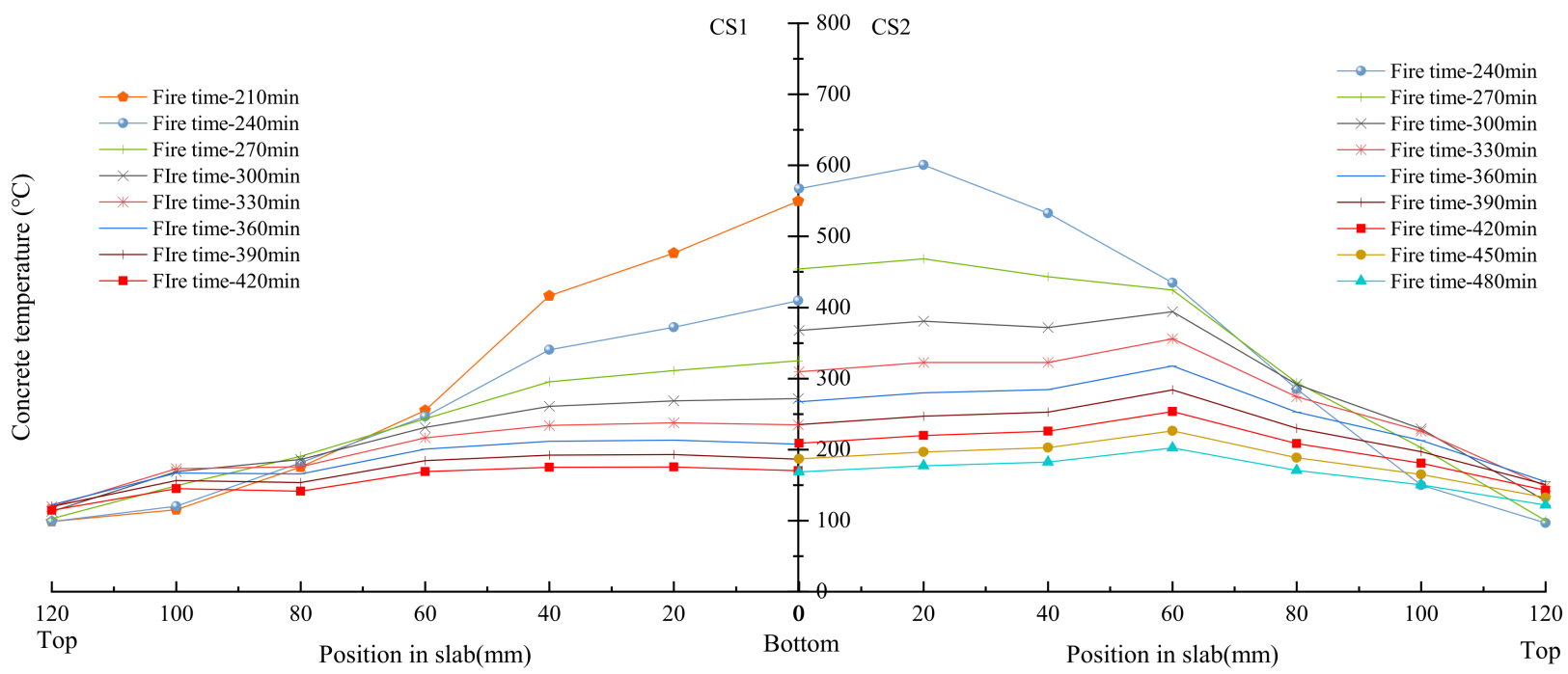

Figure 14. Temperature-time curves across the full depth of each slab at T5.

\subsubsection{Temperature of the Steel Bars}

Figure 15 shows the temperature-time relationship curve of the top and bottom steel bars of the specimen. ST6-1 is the top steel bar, and ST6-2 is the bottom steel bar. Due to the influence of crystal water in the concrete, the top steel bar experiences an obvious temperature plateau at $100{ }^{\circ} \mathrm{C}$ for approximately $30 \mathrm{~min}$. The temperature difference between the bottom layer and the top layer of the specimen increases continuously. When there is no fire exposure, the temperature difference between the bottom and top steel bars of slabs CS1 and CS2 reaches $406{ }^{\circ} \mathrm{C}$ and $447{ }^{\circ} \mathrm{C}$, respectively. Finally, according to the steel failure criterion $[44,45]$, that is, the condition steel temperature exceeds $593^{\circ} \mathrm{C}$, the fire resistance of the two concrete slabs based on the reinforcement temperature limits can be determined as shown in Table 3.

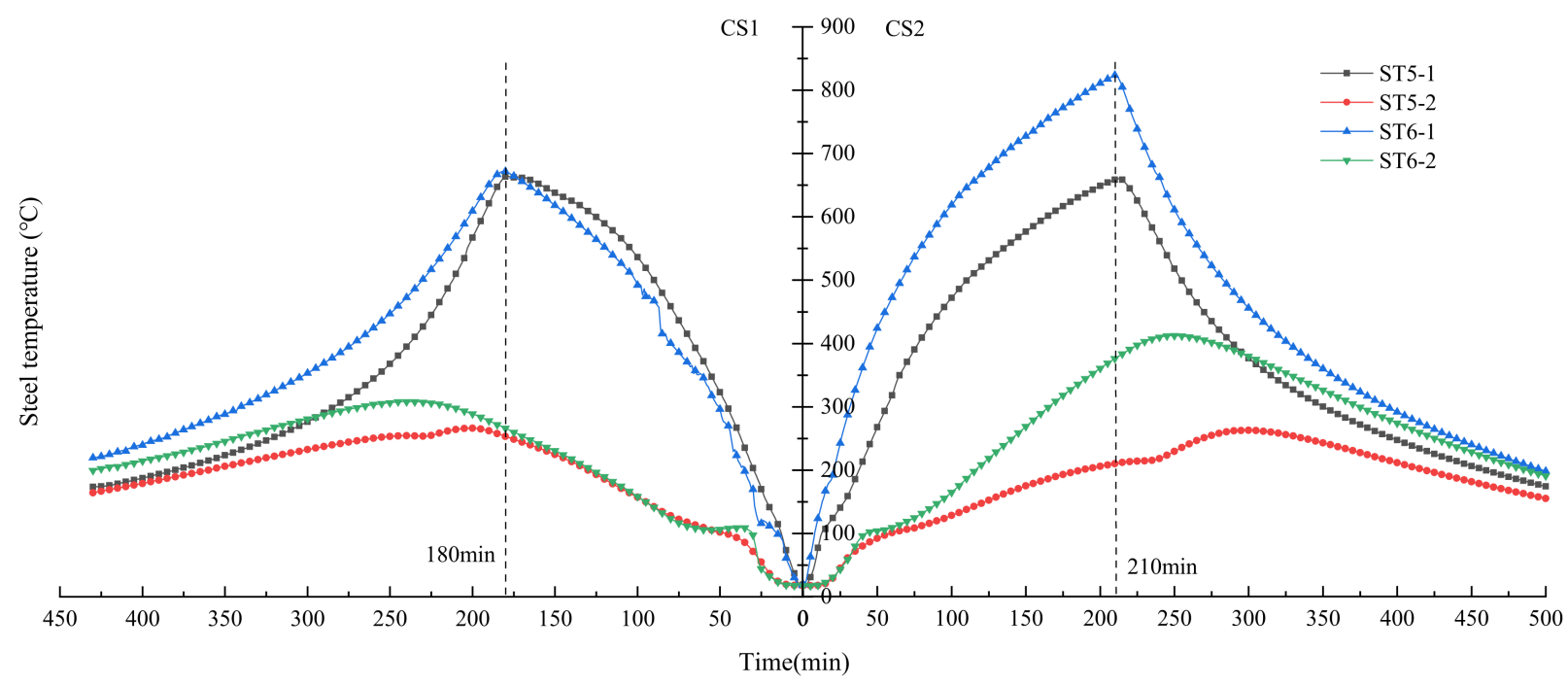

Figure 15. Temperature-time curves of the top and bottom steel bars in the specimen. 
The curves of the temperature of the steel bars versus the furnace temperature are shown in Figure 16. During the heating stage, the temperature inside the furnace is lower than $600{ }^{\circ} \mathrm{C}$, the temperature of the upper and lower layers of steel bars increases slowly, and the speed of the lower layer is slightly higher than the speed of the upper layer. When the furnace temperature is between $600{ }^{\circ} \mathrm{C}$ and $100{ }^{\circ} \mathrm{C}$, the temperature of the lower layer of the steel bars increases rapidly, but the temperature of the upper layer increases slowly. When the furnace temperature exceeds $1000^{\circ} \mathrm{C}$, the steel bar temperature increases rapidly, and the temperature of the upper and lower steel bars increases at almost the same rate.

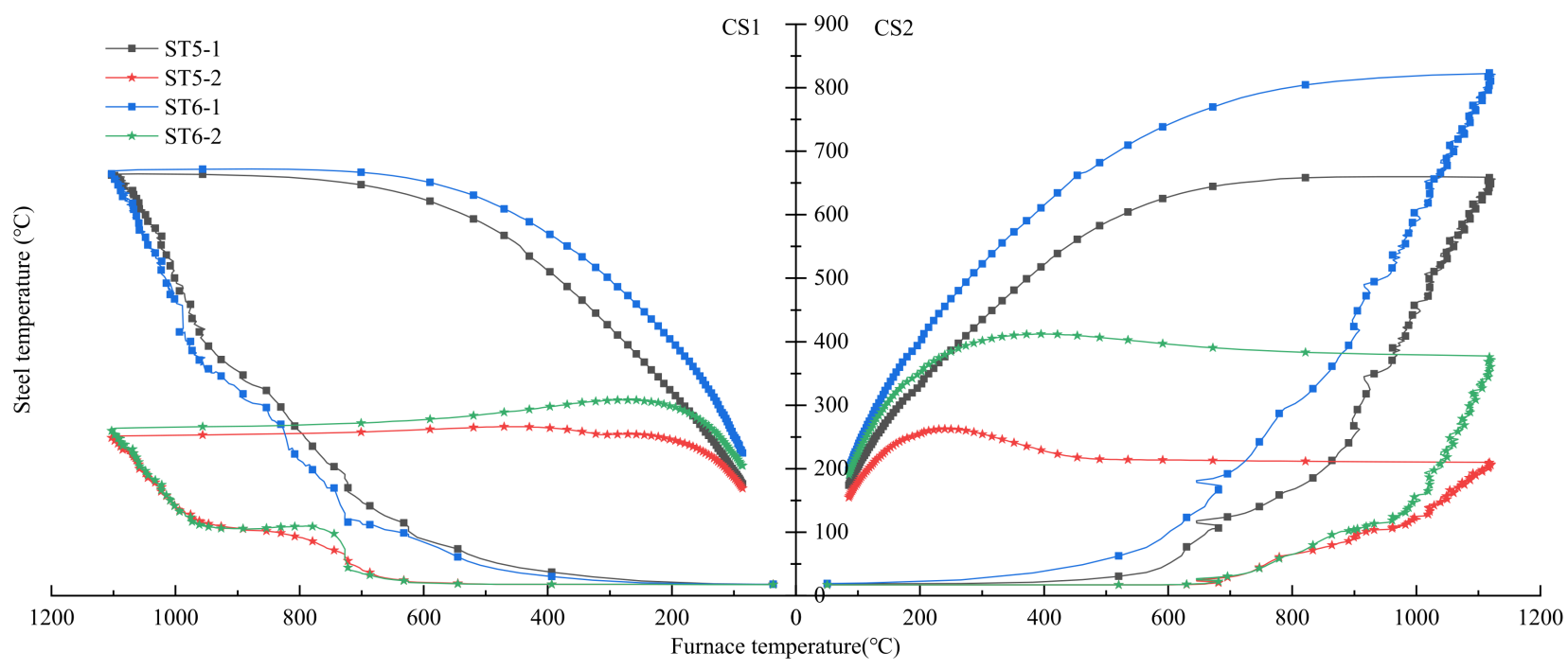

Figure 16. Curves of the temperature of the steel bars versus the furnace temperature.

\subsubsection{Out-Of-Plane Deflections}

Figure 17 shows the out-of-plane (vertical) deflections of each measuring point. During the heating stage, the deflections in the concrete slab increase rapidly in the initial $10 \mathrm{~min}$, and the maximum midspan deflections of the CS1 and CS2 slabs (V7) reach $63 \mathrm{~mm}$ $(6.3 \mathrm{~mm} / \mathrm{min})$ and $57 \mathrm{~mm}(5.7 \mathrm{~mm} / \mathrm{min})$, respectively. After $60 \mathrm{~min}$, the deflections of V7 reach $141.9 \mathrm{~mm}(1.6 \mathrm{~mm} / \mathrm{min})$ and $193.7 \mathrm{~mm}(2.7 \mathrm{~mm} / \mathrm{min})$, and the growth rate tends to be stable. At $180 \mathrm{~min}$, the deflections of V7 were $244.5 \mathrm{~mm}(0.86 \mathrm{~mm} / \mathrm{min})$ and $251.3 \mathrm{~m}$ $(0.48 \mathrm{~mm} / \mathrm{min})$, respectively. After the fire test is stopped, the deflections of CS1 and CS2 were $244.5 \mathrm{~mm}$ and $261.4 \mathrm{~mm}$, respectively. During the cooling stage, the deflections exhibited a rebound trend, which was faster in the initial stage and smoother in the later stage. When data collection stopped, the deflections of V7 were $166.8 \mathrm{~mm}$ and $180.6 \mathrm{~mm}$, respectively. The trends of the other deflection measuring points in the plate were similar to that of V7 during the heating and cooling stages. At all out-of-plane measuring points, V7 was the largest in the middle of the span, and V8, V3, and V4 decreased in turn near the $1 / 4$ span of the simply supported edge; V11 and V12 were the smallest near the 1/4 span of the clamped supported edge.

According to the deflection or deflection rate failure criteria $[45,46]$, which involve the deflection or deflection rate of the slab exceeding span/20 (or span/30) at any time, the fire resistance of each slab can be calculated as shown in Table 3.

Figure 18 shows the curve of the vertical out-of-plane deflections versus the furnace temperature. The curve shows that the growth rate of the out-of-plane deflections in the slab is low before the furnace temperature reaches $600{ }^{\circ} \mathrm{C}$ and increases when the furnace temperature is higher than $600{ }^{\circ} \mathrm{C}$. When the furnace temperature is lower than $600{ }^{\circ} \mathrm{C}$, the deflections increase, and the rebound rate accelerates. This phenomenon is due to the thermal inertia of the concrete materials. After the fire exposure stops, the temperature at the bottom of the slab decreases rapidly, but the temperature inside the slab continues to 
transmit heat to the top of the slab. The temperature of the concrete in the slab is relatively stable, and the deflections do not change greatly.

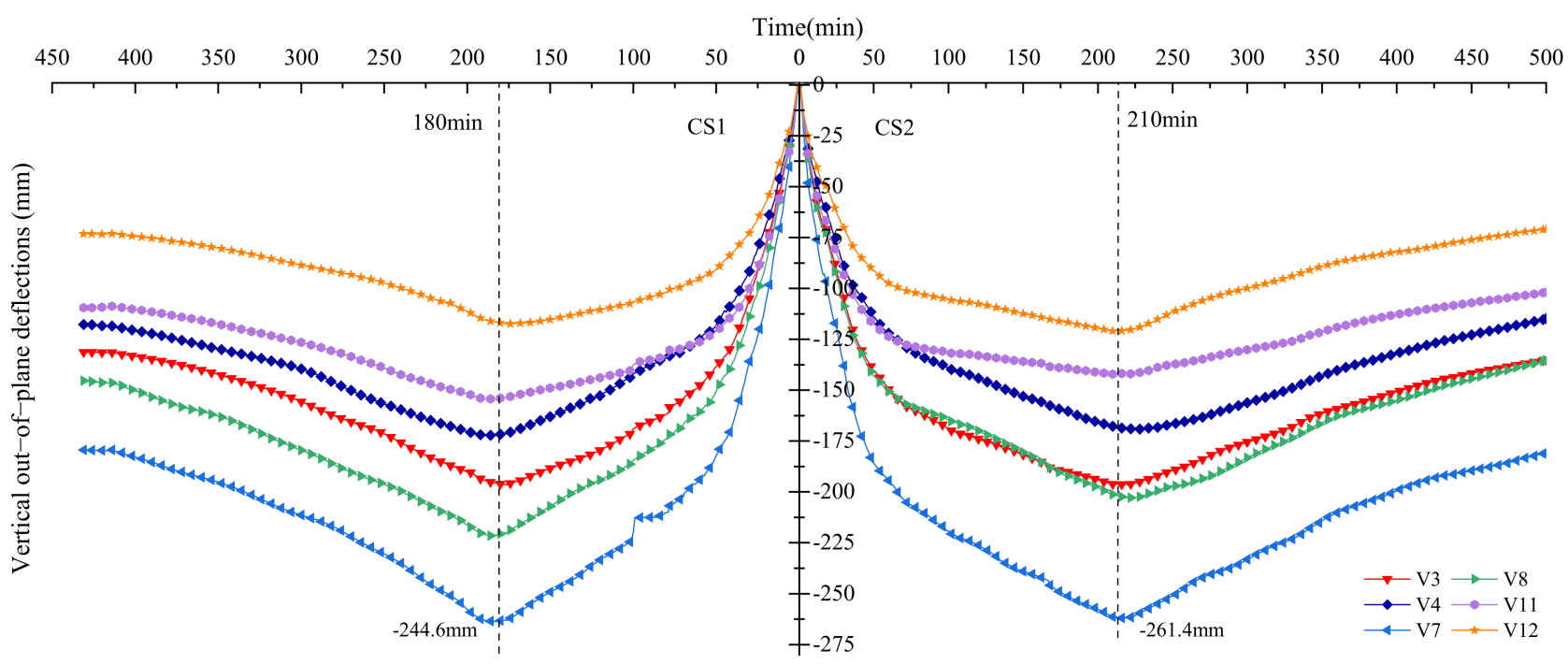

Figure 17. Curves of the vertical out-of-plane deflections versus time.

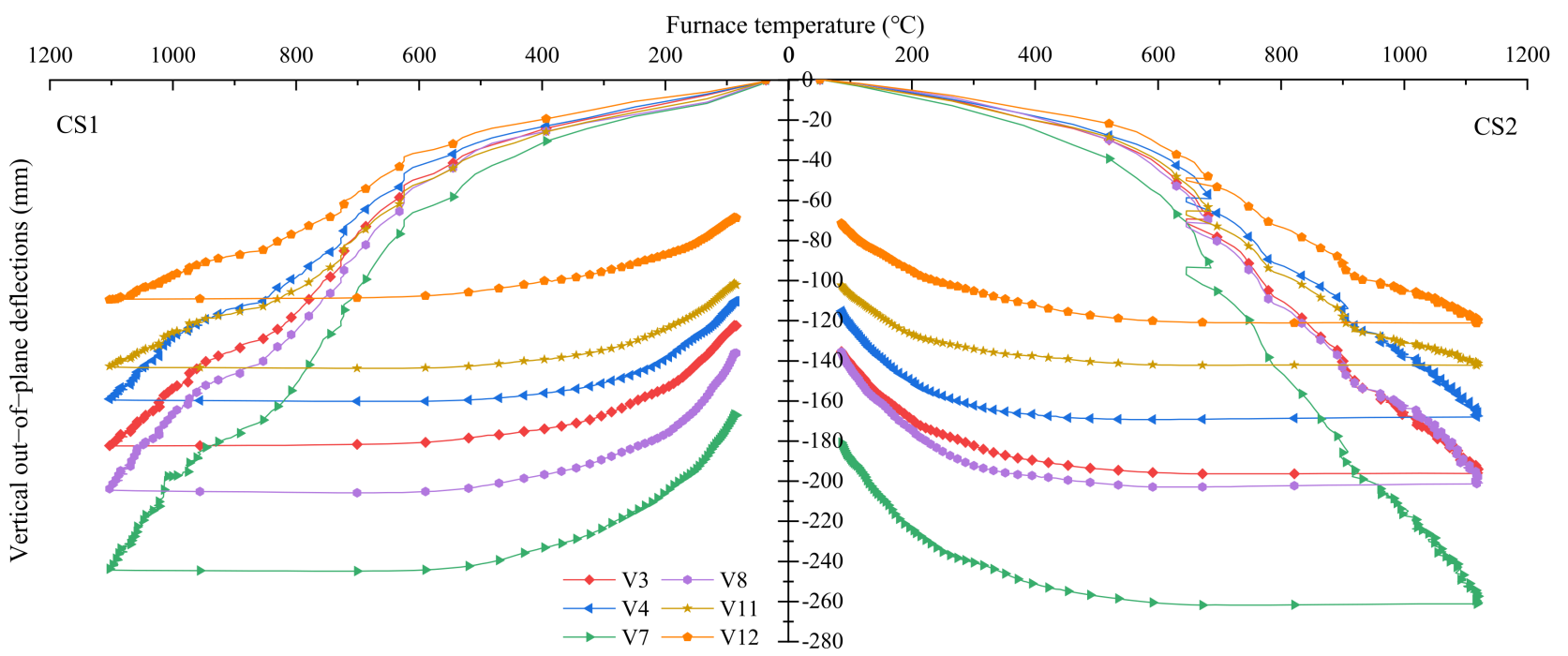

Figure 18. Curves of the vertical out-of-plane deflection versus furnace temperature.

Figure 19 shows the curves for the vertical out-of-plane deflection of the middle slab edge versus time. The results show that the edge of the concrete slab experiences a downward trend in the early stage of combustion, which is caused by the expansion of the concrete, the obvious warping of the slab corner, and the downward trend in the middle of the slab edge; however, with the increase in time of fire exposure, the deflections in the slab become larger, and the deflections of the slab edge move up relatively. When fire test stopped, the deflections of slabs CS1 and CS2 with a long simply supported side span (V1) reached $21.75 \mathrm{~mm}$ and $23.56 \mathrm{~mm}$, the deflections of the span supported on the short side (V9) reached $-0.95 \mathrm{~mm}$ and $1.47 \mathrm{~mm}$, and V13 reached $-0.53 \mathrm{~mm}$ and $2.67 \mathrm{~mm}$, respectively. The difference in the values at the edge of the slab shows that the restraint effect of the bending moment at the clamped end on the deflections at the edge of the slab is very obvious. 


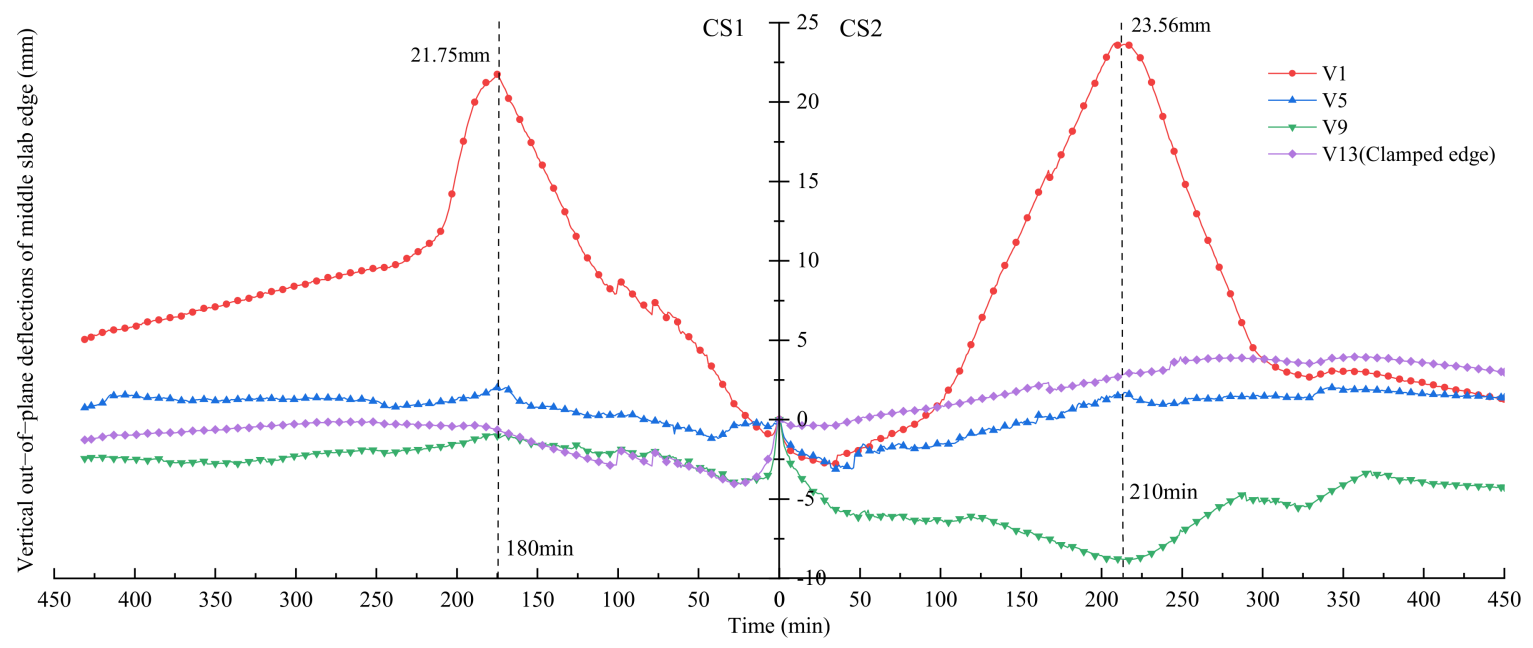

Figure 19. Curves of the vertical out-of-plane deflection at the middle of the edge of the slab versus time.

\subsubsection{In-Plane Deflections and Rotation Angle at the Support Axis}

Figure 20 shows the curve of the in-plane (horizontal) deflections with time. The negative deflections indicate that the deflections of the slab develop outward along the axis, and the positive deflections indicate that the deflection develops inward along the axis. When the fire stopped, slabs CS1 and CS2 expanded $20.36 \mathrm{~mm}$ and $17.92 \mathrm{~mm}$ along the long side and $2.39 \mathrm{~mm}$ and $0.02 \mathrm{~mm}$ along the short side. After the test, due to the decrease in the furnace temperature, the effect of thermal expansion was reduced, and $\mathrm{H} 1$ and $\mathrm{H} 2$ moved to the plate and were still in the expansion state. H3 moved slightly to the inside and then returned to the outside, and H4 moved slightly to the outside and then returned to the inside.

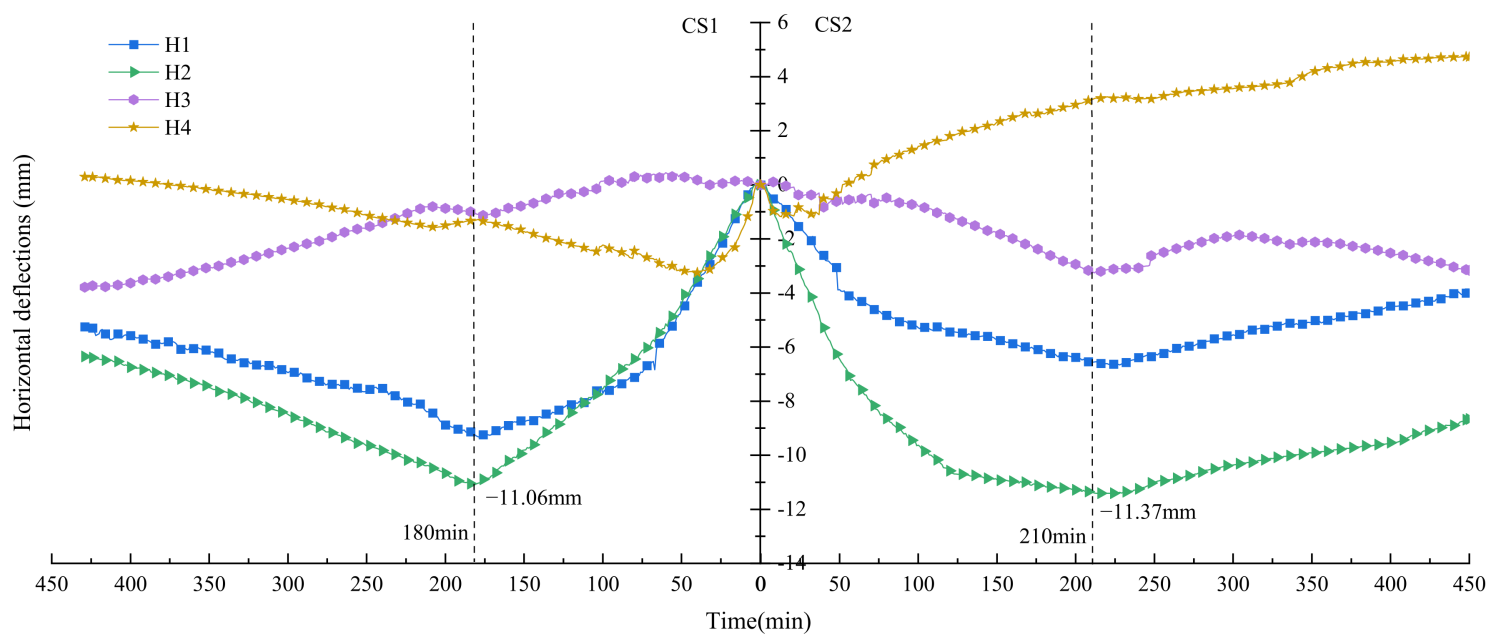

Figure 20. Curves of the horizontal deflections versus time.

Figure 21 shows the curve of the rotation angle at the supporting axis of the concrete slab with time. The deflection deformation in the slab leads to its rotation along the support axis; there is a clamped end constraint at the clamped end, which has a certain inhibition effect on the rotation of the edge of the clamped plate, and rotation angle of R4 far less than that of the three simply supported edges. There are no constraints on the long simply supported edge and the two plate angles, so rotation of R3 is the largest; the short simply supported edge has a single plate angle constraint, and the degree of rotation is in the middle compared to the rotation for other constraints. 


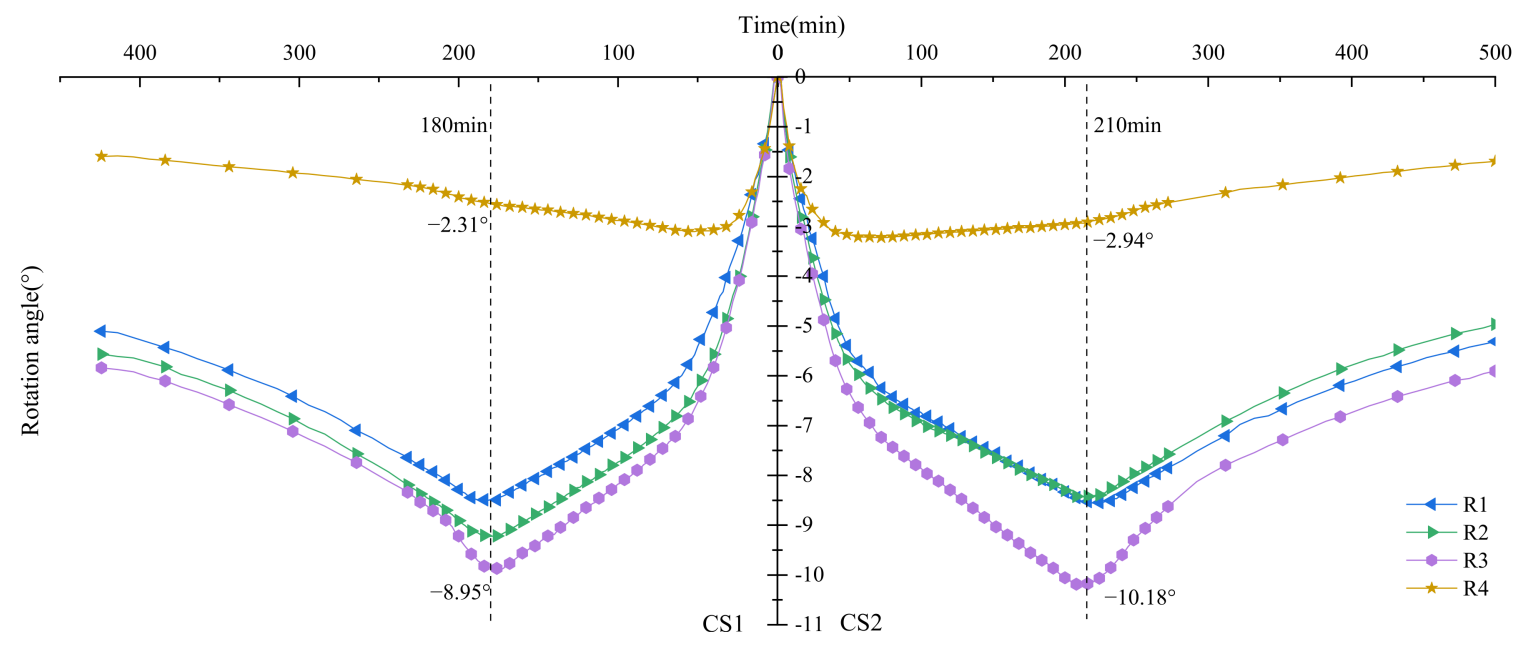

Figure 21. Corner-time curves of the two slabs.

\subsubsection{In-Plane Acceleration of the Test Slabs}

Throughout the whole test process, the change in the plate acceleration of each test plate can be divided into three stages, and slab CS1 is taken as an example for illustration. The first stage (stationary period) is from the beginning of the test to the 10th $\mathrm{min}$. In this stage, the two-way slab is not affected by fire excitation, and the acceleration information is stable. The second stage (intense stage) is from the 10th min to the 50th $\mathrm{min}$. In this stage, the bottom of the two-way slab expands, and there is a large temperature gradient in the section. Constrained by the clamped end, a large number of cracks appear on the slab surface and develop rapidly. The vertical deflections in the slab increase rapidly. Damage to the slab leads to a rapid reduction in its stiffness, and the first vertical frequency changes significantly. The third stage (stable period) is from the 50th min to the end of the test. There are basically no new cracks on the surface and bottom of the slab, the existing cracks continue to expand, and the acceleration of the slab is relatively stable.

\subsubsection{Vertical Frequency of the Test Slab}

Figure 22 and Table 4 show the change in frequency with time during the test (in Table 4, the temperature used to calculate rate of frequency reduction is the measured value of ST5-1 reinforcement temperature in the slab). The figure shows that throughout the whole test process, the change in the vertical first-order frequency of the two-way slab can also be divided into three stages.

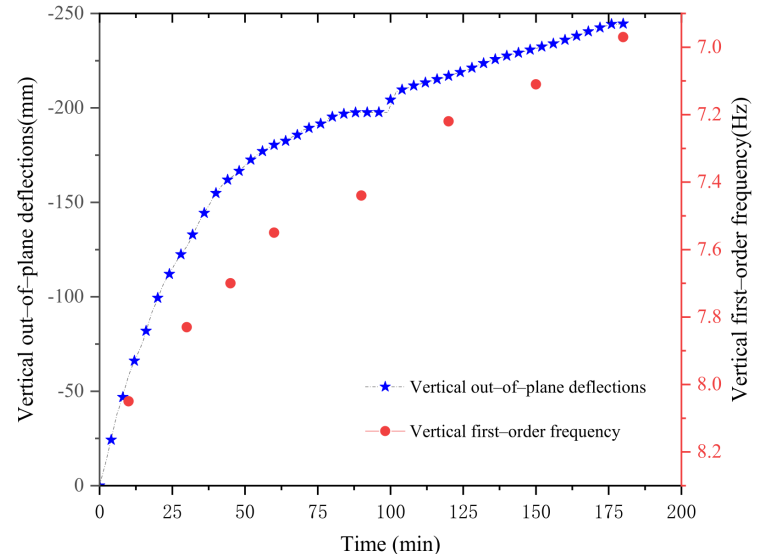

(a)

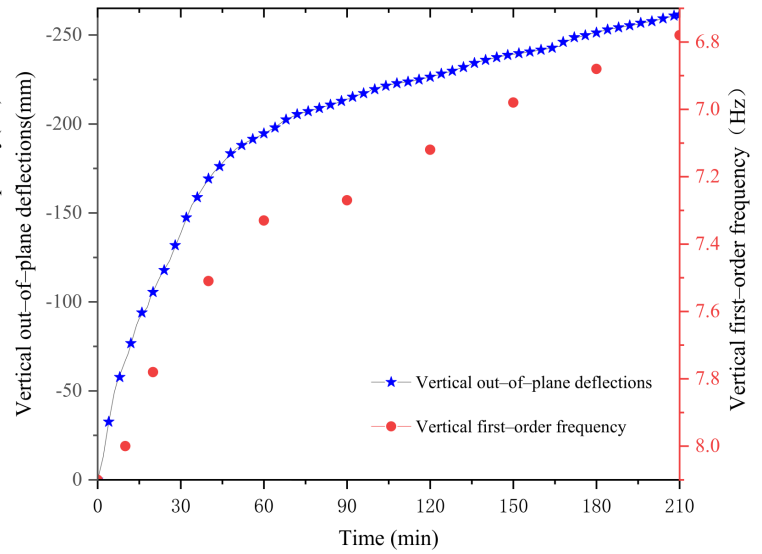

(b)

Figure 22. Measured change in the first-order vertical frequency and vertical deflection time curve of the two-way slab. (a) Slab CS1. (b) Slab CS2. 
Table 4. Vertical first-order frequency variation of two-way slabs during different periods of fire exposure.

\begin{tabular}{|c|c|c|c|c|c|c|}
\hline \multirow{3}{*}{ Specimen } & \multicolumn{6}{|c|}{ Fire Time } \\
\hline & \multicolumn{2}{|c|}{$0-60$ th $\min$} & \multicolumn{2}{|c|}{$60-150$ th $\min$} & \multicolumn{2}{|c|}{$\begin{array}{l}\text { 150th min to the Fire Test } \\
\text { Was Stopped }\end{array}$} \\
\hline & $\begin{array}{l}\text { Frequency } \\
\text { Reduction }\end{array}$ & $\begin{array}{l}\text { Rate of } \\
\text { Frequency } \\
\text { Reduction }\end{array}$ & $\begin{array}{l}\text { Frequency } \\
\text { Reduction }\end{array}$ & $\begin{array}{l}\text { Rate of } \\
\text { Frequency } \\
\text { Reduction }\end{array}$ & $\begin{array}{l}\text { Frequency } \\
\text { Reduction }\end{array}$ & $\begin{array}{l}\text { Rate of } \\
\text { Frequency } \\
\text { Reduction }\end{array}$ \\
\hline CS1 & $9.6 \%$ & $\begin{array}{l}0.16 \% / \mathrm{min}, \\
0.027 \% /{ }^{\circ} \mathrm{C}\end{array}$ & $5.3 \%$ & $\begin{array}{c}0.06 \% / \mathrm{min} \\
0.02 \% /{ }^{\circ} \mathrm{C}\end{array}$ & $1.68 \%$ & $\begin{array}{l}0.06 \% / \mathrm{min}, \\
0.067 \% /{ }^{\circ} \mathrm{C}\end{array}$ \\
\hline CS2 & $9.5 \%$ & $\begin{array}{l}0.16 \% / \mathrm{min}, \\
0.032 \% /{ }^{\circ} \mathrm{C}\end{array}$ & $4.3 \%$ & $\begin{array}{l}0.05 \% / \mathrm{min}, \\
0.017 \% /{ }^{\circ} \mathrm{C}\end{array}$ & $2.5 \%$ & $\begin{array}{l}0.04 \% / \mathrm{min}, \\
0.0005 \% /{ }^{\circ} \mathrm{C}\end{array}$ \\
\hline
\end{tabular}

The initial stage is from the beginning of the test to the 60th min. In this stage, the bottom of the two-way slab is subject to fire expansion, there is a large temperature gradient in the cross section, and a large number of cracks appear on the slab surface and develop rapidly because the surface is constrained by the clamped end. The vertical deflections in the slab increase rapidly. Damage to the slab leads to a rapid reduction in its stiffness, and the corresponding first-order vertical self-excitation frequency changes significantly. The second stage is from the 60th min to the 150th min. In this stage, the vertical deflections increase slowly, and the self-excitation frequency decreases correspondingly. During this period, no new cracks appear on the slab surface, and the existing cracks continue to expand. As the in-plane membrane effect in the central region of the plate changes from compression to tension, the tensile membrane effect develops gradually, the growth rate of the vertical deflections decreases, and the stiffness attenuation rate of the plate decreases significantly compared with the previous stage. The third stage is from the 150th min to the end of the fire test. In this stage, the vertical deflections increase slowly and linearly, and the vertical frequencies of the slabs decrease slightly, which also reflects the slow attenuation of the stiffness of the slab. Throughout the whole test process, the frequency attenuation of the slab is large, which indicates that the stiffness of the slab experiences great loss under the action of fire.

Figure 22 shows that the variation in the vertical first-order frequency of the twoway slab is consistent with the variation law of the vertical deflections in the slab, and Figure 23 shows the relationship between change in the frequency and change in the vertical deflection of the two-way slab under fire conditions.

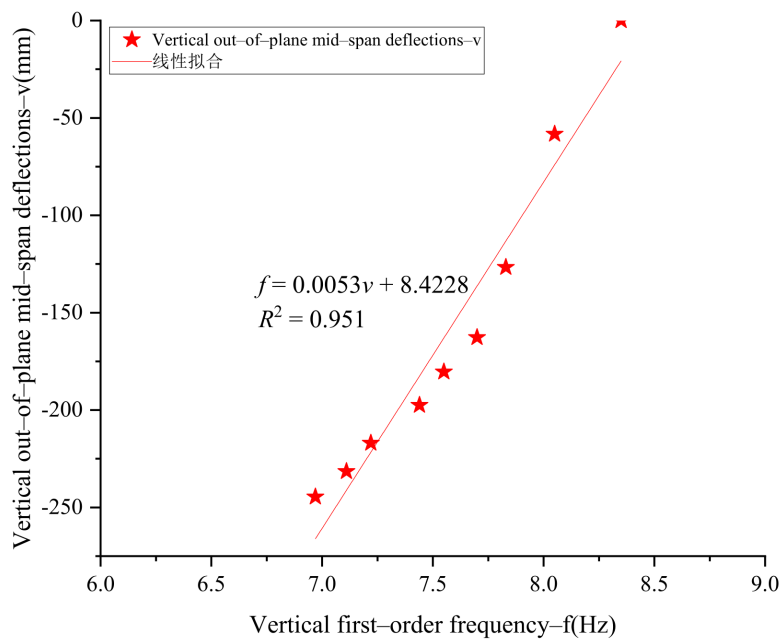

(a)

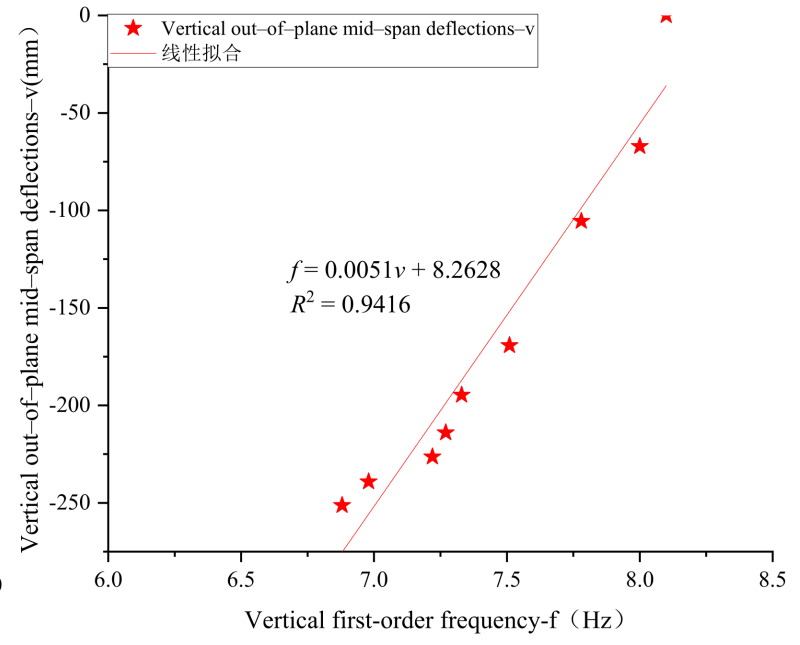

(b)

Figure 23. Relationship between the change in the frequency and change in the vertical deflection of the two-way slab under fire exposure. (a) Slab CS1. (b) Slab CS2. 


\section{Calculation of Bearing Capacity Based on Yield Hinge Line Theory}

Basic assumptions [19,20,24]: The failure of the stiffened plate starts from the yield of tensile reinforcement. In case of failure, plastic deformation and yield of tensile reinforcement occur at the yield hinge line. No strain-hardening of reinforcement occurs. Based on the classical yield hinge line theory, the failure mode of two-way slabs with three simply supported edges and one clamped edge under fire is shown in Figure 24. In the figure, A-B, $\mathrm{B}-\mathrm{C}, \mathrm{A}-\mathrm{O}, \mathrm{A}-\mathrm{E}, \mathrm{B}-\mathrm{D}, \mathrm{E}-\mathrm{D}, \mathrm{O}-\mathrm{E}, \mathrm{C}-\mathrm{D}$ are the positive yield hinge line and $\mathrm{O}-\mathrm{C}$ is the negative yield hinge line.

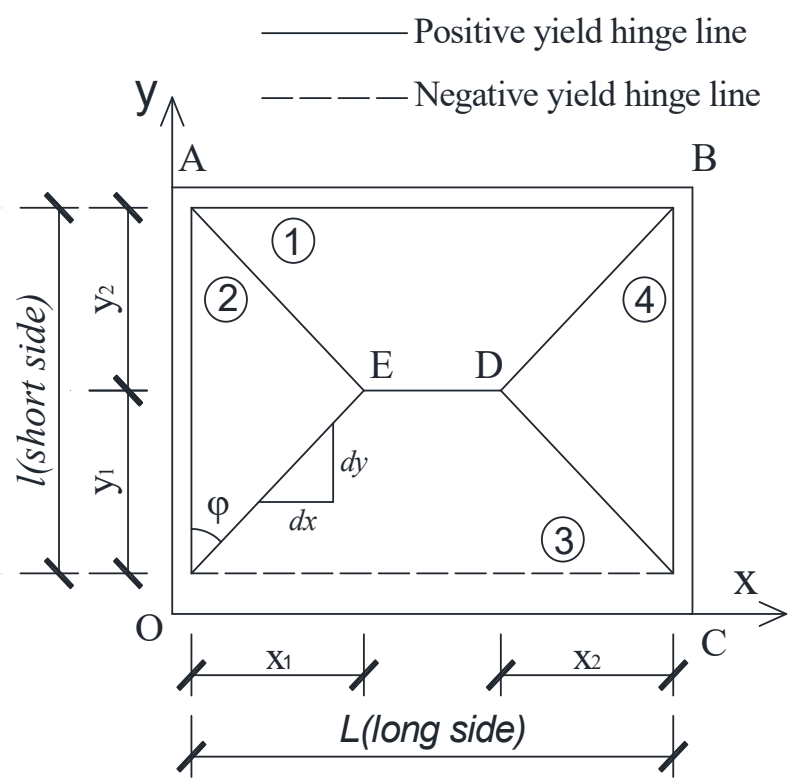

Figure 24. Yield hinge line configuration of the slab with three simply supported edges and one clamped edge.

When the vertical out-of-plane mid-span deflection of the two-way slab reaches $v$, direction of reinforcement resultant force no longer remains horizontal, but it will form an angle $(\theta)$ with the horizontal direction, and the vertical component is generated (see Figures 25 and 26). With the continuous increase of vertical displacement in the slab and the continuous increase of reinforcement temperature at the bottom of the slab, the resultant force of concrete pressure $(C)$ and reinforcement $(T)$ continues to decrease, the vertical component of reinforcement $(T \sin \theta)$ continues to increase, the membrane effect continues to strengthen, and the limit carrying capacity of the slab also increases accordingly $[19,20]$.

q

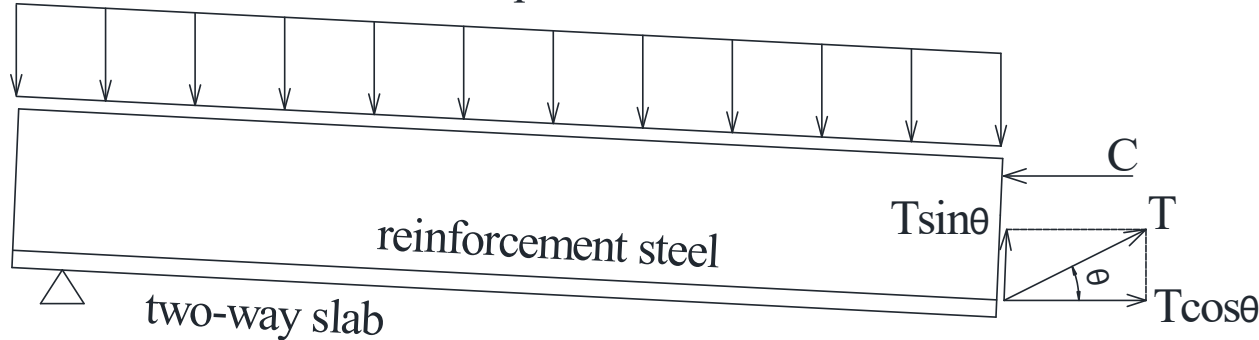

Figure 25. Forces at the yield hinge section of the slab. 


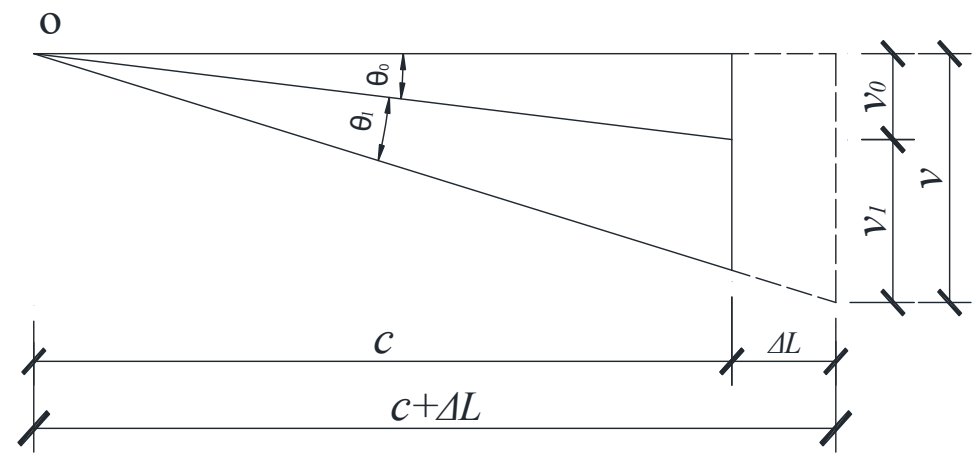

Figure 26. Diagram of vertical displacement and rotation angle ( $v_{0}$ is vertical out-of-plane deflection of slab at formation of mechanism of the plastic hinge line).

\subsection{Plate Balance Method}

At room temperature:

The equilibrium Equation of plate (1) rotating around $A B$ axis is:

$$
m_{y} L=\frac{1}{6} x_{1} y_{2}^{2} q+\frac{1}{2}\left(L-x_{1}-x_{2}\right) y_{2}^{2} q+\frac{1}{6} x_{2} y_{2}^{2} q
$$

The equilibrium Equation of plate (2) rotating around $\mathrm{AO}$ axis is:

$$
m_{x} l=\frac{1}{6} x_{1}^{2} l q
$$

The equilibrium Equation of plate (3) rotating around OC axis is:

$$
\left(m_{y e}^{\prime}+m_{y}\right) L=\frac{1}{6} x_{1} y_{1}^{2} q+\frac{1}{2}\left(L-x_{1}-x_{2}\right) y_{1}^{2} q+\frac{1}{6} x_{2} y_{1}^{2} q
$$

The equilibrium Equation of plate (4) rotating around CA axis is:

$$
m_{x} l=\frac{1}{6} x_{2}^{2} l q
$$

where $m_{x}$ is $x$-direction moment of resistance per length at yield hinge line section; $m_{y}$ is $y$-direction moment of resistance per length at yield hinge line section; $m_{x T}$ is $x$-direction moment of resistance per length at yield hinge line section at elevated temperatures; $m_{y T}$ is $y$-direction moment of resistance per length at yield hinge line section at elevated temperatures; $m_{y e}^{\prime}$ is $y$-direction negative moment at the axis of the clamped support; $q$ is carrying capacity of the concrete slab, including dead load of slab and live load of slab surface.

It can be seen from the geometric relationship of plates: $x_{1}=x_{2}$.

It can be solved from Equations (1)-(4):

$$
\begin{gathered}
x_{1}=x_{2}=\frac{-2 l^{2} m_{x}+l \sqrt{m_{x}+3 L^{2} m_{x}}}{L\left(\sqrt{m_{y}}+\sqrt{m_{y e}+m_{y}}\right)^{2}} \\
y_{1}=\frac{l \sqrt{m_{y}+m_{y e}}}{\sqrt{m_{y}}+\sqrt{m_{y}+m_{y e}}}
\end{gathered}
$$

After the yield hinge line is formed in the concrete slab, the position of the yield hinge line has been determined, and the position will not change with the increase of deflection. Therefore, the calculated value and at room temperature can be used to calculate the ultimate bearing capacity of the two-way slab at high temperature. 
Under high temperature, the vertical component of tensile reinforcement participates in the stress, and membrane effect is generated in the plate. Equations (1)-(4) should change to:

$$
\begin{gathered}
m_{y T} L+\frac{1}{2} y_{2}\left(x_{1}+x_{2}\right) T_{y T} \sin \theta_{1}+\left(L-x_{1}-x_{2}\right) y_{2} T_{y T} \sin \theta_{1}=\frac{1}{6} x_{1} y_{2}^{2} q+\frac{1}{2}\left(L-x_{1}-x_{2}\right) y_{2}^{2} q+\frac{1}{6} x_{2} y_{2}^{2} q \\
m_{x T} l+\frac{1}{2} x_{1} T_{x T} l \sin \theta_{2}=\frac{1}{6} x_{1}^{2} l q \\
\left(m_{y e}^{\prime}+m_{y T}\right) L+\frac{1}{2} y_{1}\left(x_{1}+x_{2}\right) T_{y T} \sin \theta_{3}+y_{1}\left(L-x_{1}-x_{2}\right) T_{y T} \sin \theta_{3}=\frac{1}{6} x_{1} y_{1}^{2} q+\frac{1}{2}\left(L-x_{1}-x_{2}\right) y_{1}^{2} q+\frac{1}{6} x_{2} y_{1}^{2} q \\
m_{x T} l+\frac{1}{2} x_{2} T_{x T} l \sin \theta_{4}=\frac{1}{6} x_{2}^{2} l q
\end{gathered}
$$

where $T_{x}$ is $x$-direction reinforcement tensile force per length at plastic hinge line section; $T_{x T}$ is $x$-direction reinforcement tensile force per length at plastic hinge line section elevated; $T_{y}$ is $x$-direction reinforcement tensile force per length at plastic hinge line section; $T_{y T}$ is $x$-direction reinforcement tensile force per length at plastic hinge line section elevated.

$$
\begin{gathered}
\sin \theta_{1}=\frac{v}{\sqrt{y_{2}^{2}+v^{2}}} \sin \theta_{2}=\frac{v}{\sqrt{x_{1}^{2}+v^{2}}}, \sin \theta_{3}=\frac{v}{\sqrt{y_{1}^{2}+v^{2}}}, \sin \theta_{4}=\frac{v}{\sqrt{x_{2}^{2}+v^{2}}} \\
q_{1}=\frac{6 m_{y T} L+6 y_{2} T_{y T} L \frac{v-v_{0}}{\sqrt{y_{2}^{2}+v^{2}}}-6 x_{1} y_{2} T_{y T} \frac{v-v_{0}}{\sqrt{y_{2}^{2}+v^{2}}}}{3 L y_{2}^{2}-4 x_{1} y_{2}^{2}} \\
q_{2}=q_{4}=\frac{6 m_{x T}+3 x_{1} T_{x T} \frac{v-v_{0}}{\sqrt{x_{1}^{2}+v^{2}}}}{x_{1}^{2}} \\
q_{3}=\frac{6\left(m_{y T}+m_{y e}\right) L+6 y_{2} T_{y T} L \frac{v-v_{0}}{\sqrt{y_{2}^{2}+v^{2}}}-6 x_{1} y_{2} T_{y T} \frac{v-v_{0}}{\sqrt{y_{2}^{2}+v^{2}}}}{3 L y_{2}^{2}-4 x_{1} y_{2}^{2}}
\end{gathered}
$$

where $q_{i}$ is limit load-carrying capacity of plate $i$.

The limit load-carrying capacity of two-way slabs with three simply supported edges and one clamped edge is:

$$
q=\min \left(q_{1}, q_{2}, q_{3}, q_{4}\right)
$$

where $v_{0}$ is taken as [46]:

$$
v_{0}=\sqrt{\left(\frac{0.1 f_{y}}{E}\right) \frac{3 L^{2}}{8}}
$$

\subsection{Energy Method}

In the case of large deflection, the tension film effect of the plate occurs after the yield hinge line appears, and the reason for the film effect is the plastic work conducted by the elongation of the yield reinforcement at the section of the yield hinge line [19]. Work conducted by reinforcement elongation when the yield hinge line rotates around axes $\mathrm{AB}$ and $\mathrm{BC}$ :

$$
\begin{gathered}
\int_{0}^{y_{1}} \int_{0}^{v} T_{x T} d y d e(x)=\int_{0}^{x_{1}} \int_{0}^{v} T_{x T} \frac{d x}{\tan \varphi}\left\{\sqrt{x^{2}+\left[\frac{x}{x_{1 T}}(z+d z)\right]^{2}}-\sqrt{x^{2}+\left(\frac{x}{x_{1 T}} z\right)^{2}}\right\}=\frac{T_{x T}}{2} y_{1}\left(\frac{v^{2}}{\sqrt{x_{1 T}^{2}+v^{2}}+x_{1 T}}\right) \\
\int_{0}^{x_{1}} \int_{0}^{v} T_{y T} d y d e(y)=\int_{0}^{y_{1}} \int_{0}^{v} T_{y T} d y \tan \varphi\left\{\sqrt{y^{2}+\left[\frac{y}{y_{1 T}}(z+d z)\right]^{2}}-\sqrt{y^{2}+\left(\frac{y}{y_{1 T}} z\right)^{2}}\right\}=\frac{T_{y T}}{2} x_{1}\left(\frac{v^{2}}{\sqrt{y_{1 T}^{2}+v^{2}}+y_{1 T}}\right)
\end{gathered}
$$


Work conducted by plastic hinge wire $\mathrm{AD}$ rotating around axes $\mathrm{AO}$ and $\mathrm{AB}$ and steel bar elongation:

$$
\begin{aligned}
& \frac{T_{x T}}{2} y_{2}\left(\frac{v^{2}}{\sqrt{x_{1 T}^{2}+v^{2}}+x_{1 T}}\right) \\
& \frac{T_{y T}}{2} x_{2}\left(\frac{v^{2}}{\sqrt{y_{1 T}^{2}+v^{2}}+y_{1 T}}\right)
\end{aligned}
$$

Work conducted by yield hinge line $\mathrm{CD}$ rotating reinforcement elongation around axes BC and OC:

$$
\begin{aligned}
& \frac{T_{x T}}{2} y_{1}\left(\frac{v^{2}}{\sqrt{x_{2 T}^{2}+v^{2}}+x_{2 T}}\right) \\
& \frac{T_{y T}}{2} x_{1}\left(\frac{v^{2}}{\sqrt{y_{2 T}^{2}+v^{2}}+y_{2 T}}\right)
\end{aligned}
$$

Work conducted by reinforcement elongation when plastic hinge BD rotates around axes $\mathrm{BC}$ and $\mathrm{AB}$ :

$$
\begin{aligned}
& \frac{T_{x T}}{2} y_{2}\left(\frac{v^{2}}{\sqrt{x_{2 T}^{2}+v^{2}}+x_{2 T}}\right) \\
& \frac{T_{y T}}{2} x_{2}\left(\frac{v^{2}}{\sqrt{y_{2 T}^{2}+v^{2}}+y_{2 T}}\right)
\end{aligned}
$$

Work conducted by reinforcement elongation when yield hinge line DE rotates around axes $\mathrm{AO}$ and $\mathrm{BC}$ :

$$
\begin{array}{r}
\int_{x_{1}}^{L-x_{2}} \int_{0}^{v} T_{y T} d x d e(y)=\int_{x_{1}}^{L-x_{2}} \int_{0}^{v} T_{y T} d x\left\{\sqrt{y^{2}+\left[\frac{y}{y_{1 T}}(z+d z)\right]^{2}}-\sqrt{y^{2}+\left(\frac{y}{y_{1 T}} z\right)^{2}}\right\}=T_{y T}\left(L-x_{1}-x_{2}\right)\left(\frac{v^{2}}{\sqrt{y_{1 T}^{2}+v^{2}+y_{1 T}}}\right) \\
T_{y T}\left(L-x_{1}-x_{2}\right)\left(\frac{v^{2}}{\sqrt{y_{1 T}^{2}+v^{2}}+y_{1 T}}\right)
\end{array}
$$

where $x_{i T}=x_{i}+\alpha_{1}(T-20) x_{i}, y_{i T}=y_{i}+\alpha_{1}(T-20) y_{i}$, where $\alpha_{1}$ is coefficient of thermal expansion; $x_{i}$ and $y_{i}$ are obtained by the plate balance method.

The work performed by uniformly distributed external load can be expressed:

$$
W=\frac{1}{6} q l v\left[3 L-\left(x_{1}+x_{2}\right)\right]
$$

The work performed by resultant moment:

$$
D_{1}=m_{x T} l \frac{v}{x_{1}}+m_{x T} l \frac{v}{x_{2}}+m_{y T} x_{1} \frac{v}{y_{1}}+m_{y T} x_{2} \frac{v}{y_{1}}+m_{y T} x_{1} \frac{v}{y_{2}}+m_{y T} x_{2} \frac{v}{y_{2}}+m_{y e} L \frac{v}{y_{1}}
$$

Work performed by reinforcement elongation:

$$
D_{2}=\frac{T_{x T}}{2} l\left(\frac{v^{2}}{\sqrt{x_{1 T}^{2}+v^{2}}+x_{1 T}}\right)+\frac{T_{x T}}{2} l\left(\frac{v^{2}}{\sqrt{x_{2 T}^{2}+v^{2}}+x_{2 T}}\right)+\frac{T_{y T}}{2}\left(2 L-x_{1}-x_{2}\right)\left(\frac{v^{2}}{\sqrt{y_{1 T}^{2}+v^{2}}+y_{1 T}}\right)+\frac{T_{y T}}{2}\left(2 L-x_{1}-x_{2}\right)\left(\frac{v^{2}}{\sqrt{y_{2 T}^{2}+v^{2}}+y_{2 T}}\right)
$$

Work performed by external force is equal to work done by internal force:

$$
W=D_{1}+D_{2}
$$


The limit carrying capacity of two-way slabs with three simply supported edges and one clamped edge can be obtained from Equations (27)-(29):

$$
\begin{gathered}
q=\frac{6}{l\left[3 L-\left(x_{1}+x_{2}\right)\right]}\left\{\frac{m_{x T} l}{x_{1}}+\frac{m_{x T} l}{x_{2}}+\frac{m_{y T} L}{y_{1}}+\frac{m_{y T} L}{y_{2}}+\frac{m_{y e} L}{y_{1}}+\frac{m_{y e} L}{y_{2}}+\sum_{i=1}^{4} m_{p i}\right\} \\
m_{p 1}=\frac{T_{y T}}{2}\left(2 L-x_{1}-x_{2}\right)\left(\frac{v-v_{0}}{\sqrt{y_{2 T}^{2}+v^{2}}+y_{2 T}}\right) \\
m_{p 2}=\frac{T_{x T}}{2} l\left(\frac{v-v_{0}}{\sqrt{x_{1 T}^{2}+v^{2}}+x_{1 T}}\right) \\
m_{p 3}=\frac{T_{y T}}{2}\left(2 L-x_{1}-x_{2}\right)\left(\frac{v-v_{0}}{\sqrt{y_{1 T}^{2}+v^{2}}+y_{1 T}}\right) \\
m_{p 4}=\frac{T_{x T}}{2} l\left(\frac{v-v_{0}}{\sqrt{x_{2 T}^{2}+v^{2}}+x_{2 T}}\right)
\end{gathered}
$$

\subsection{Verification}

Figures 27 and 28 show the relationship between the calculated carrying capacity of two-way slab specimens under fire and the temperature change of bottom reinforcement based on plate balance method and energy method, respectively. The traditional method in the figure is the yield hinge line theoretical formula, without considering the tensile membrane effect. Table 5 shows the comparison of limit carrying capacity of two-way slabs under fire.

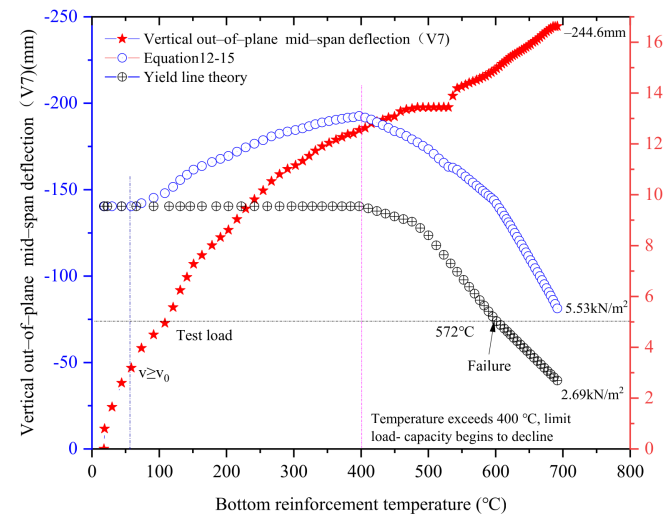

(a)

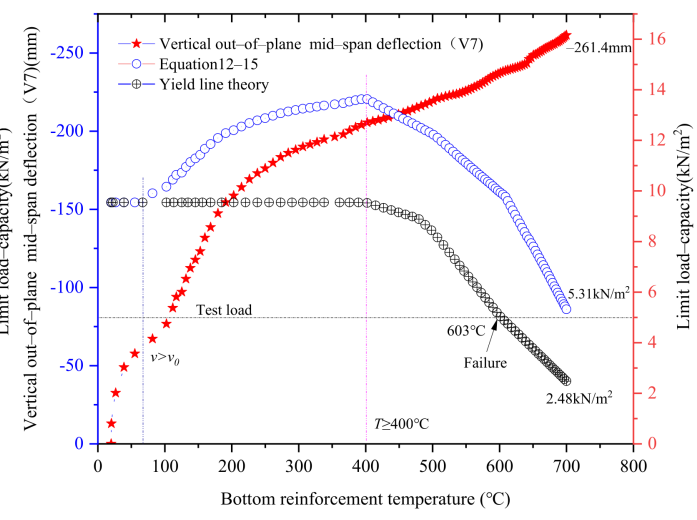

(b)

Figure 27. Curve of bearing capacity with temperature (plate balance method). (a) Slab CS1. (b) Slab CS2.

As can be seen from Figures 27 and 28, when the temperature of the bottom reinforcement exceeds $400{ }^{\circ} \mathrm{C}$, the limit carrying capacity of the slab decreases rapidly. This is because the yield strength of the reinforcement will be rapidly reduced when temperature exceeds $400{ }^{\circ} \mathrm{C}$ [47]. According to the limit load-carrying capacity calculated by the formula in this paper, when the vertical out-of-plane mid-span deflection is lower than $v_{0}$, the carrying capacity is constant. However, when the vertical out-of-plane mid-span deflection is higher than $v_{0}$, the carrying capacity of the slab begins to increase because the membrane effect of the slab begins to appear. 


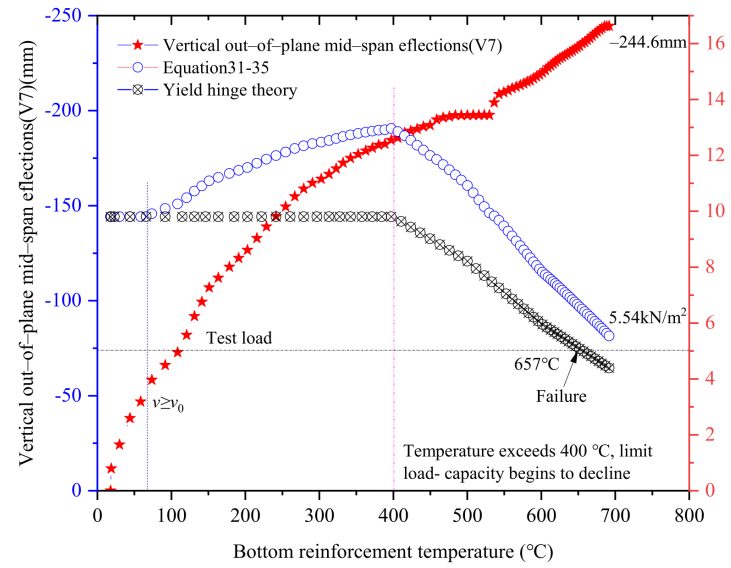

(a)

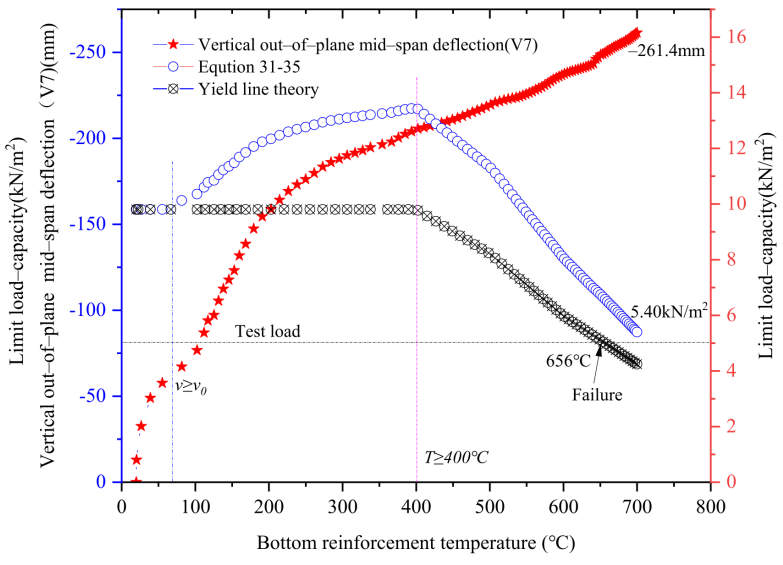

(b)

Figure 28. Curve of bearing capacity with temperature (energy method). (a) Slab CS1. (b) Slab CS2.

Table 5. Comparison of ultimate bearing capacity of two-way slabs under fire.

\begin{tabular}{ccccccccc}
\hline & & \multicolumn{2}{c}{ Fire Test Was Stopped } & \multicolumn{4}{c}{$q_{\text {limt }} /$ Mpa } \\
\cline { 3 - 8 } No & $\begin{array}{c}\text { Support } \\
\text { Axis/mm }\end{array}$ & $\begin{array}{c}\text { Vertical } \\
\text { Out-of-Plane } \\
\text { Deflection/mm }\end{array}$ & $\begin{array}{c}\text { Temperature } \\
\text { of the Bottom } \\
\text { Steel Bars } /{ }^{\circ} \mathbf{C}\end{array}$ & $\begin{array}{c}\text { Plate Balance Method } \\
\text { Yield Line } \\
\text { Theory (1) }\end{array}$ & $\begin{array}{c}\text { Equation } \\
\text { (15) (2) }\end{array}$ & $\begin{array}{c}\text { Energy Method } \\
\text { Yield Line } \\
\text { Theory (3) }\end{array}$ & $\begin{array}{c}\text { Equation } \\
\text { (30) (4) }\end{array}$ & (4)/(2) \\
\hline CS1 & $7150 \times$ & 244.6 & 692 & 2.69 & 5.53 & 4.39 & 5.54 \\
CS2 & 5650 & 261.4 & 700 & 2.48 & 5.31 & 4.25 & 5.40 \\
\hline
\end{tabular}

According to the calculation based on the traditional plate balance method, the slabs CS1 and CS2 are damaged when the bottom reinforcement temperature is $572{ }^{\circ} \mathrm{C}$ and $603{ }^{\circ} \mathrm{C}$; that is, the limit carrying capacity is lower than $5.00 \mathrm{kN} / \mathrm{m}^{2}$, and the vertical out-of-plane mid-span deflections of each slab corresponding to the reinforcement temperature are span/28 and span/24, respectively, which has not exceeded the deflection limit of span/20 [48-50], and the slab still has a certain fire resistance. It is obvious that a traditional calculation method does not consider the improvement of the bearing capacity of the two-way slab membrane effect at high temperature, which leads to the conservative calculation results. According to the calculation formula proposed in this paper, the limit bearing capacity of the specimen when the fire turned off are $5.53 \mathrm{kN} / \mathrm{m}^{2}$ and $5.31 \mathrm{kN} / \mathrm{m}^{2}$, respectively, and the corresponding vertical out-of-plane mid-span deflections are span $/ 22$ and span/23, respectively, which is basically consistent with the test results.

According to the calculation based on the traditional energy method, the slab CS1 and CS2 are damaged when the bottom reinforcement temperature reaches $657^{\circ} \mathrm{C}$ and $656^{\circ} \mathrm{C}$ and the vertical out-of-plane mid-span deflections of each slab corresponding to the reinforcement temperature is span/22 and span/24, respectively, which has not reached the failure criterion of the two-way slab (span/20). As can be seen, there are problems between the traditional energy method and the traditional plate balance method. The calculation results are still conservative, but the deviation degree is lower than that of the plate balance method. According to the calculation formula proposed in this paper, the limit load-carrying capacity of the slabs when the fire is turned off is $5.54 \mathrm{kN} / \mathrm{m}^{2}$ and $5.40 \mathrm{kN} / \mathrm{m}^{2}$, respectively, which is slightly larger than the calculated value of the plate balance method proposed in this paper, with a deviation of about $0.2 \sim 1.7 \%$, which is basically consistent with the test results.

Figure 29 shows the comparison of the calculation results of the carrying capacity of the two slabs obtained by Equation (15) when the vertical out-of-plane mid-span deflections is span/15, span/20, span/25, span/30, and span/35, respectively. The temperature of reinforcement at the bottom of the slab shall be taken as the test result. Calculation result of 
carrying capacity is close to $5.00 \mathrm{kN} / \mathrm{m}^{2}$ (at the time the fire test is stopped) when the given vertical displacement of slab CS1 (CS2) is between span/25 span/30 (span/20 span/25), which has a certain deviation from the failure criterion of vertical displacement. The reason for the deviation is temperature of reinforcement at the bottom of slab CS1 and CS2 is much lower, and the yield strength of reinforcement will decrease significantly with the increase of temperature.

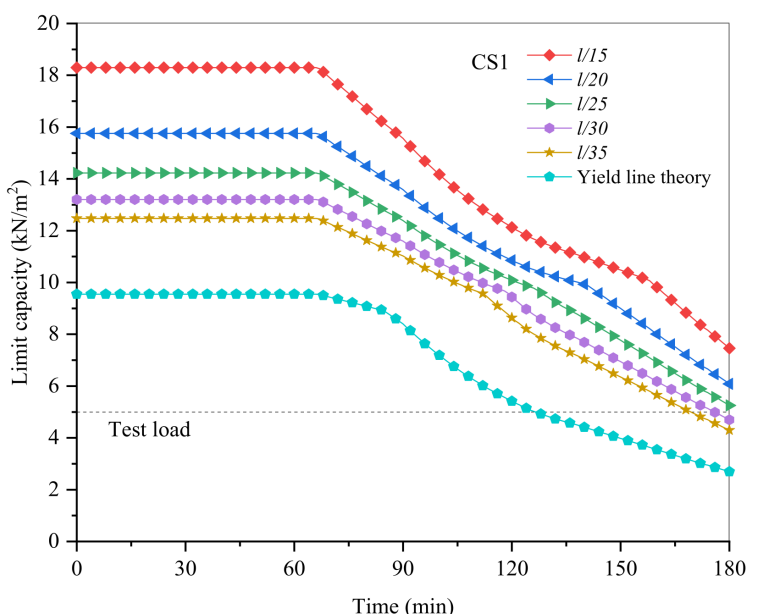

(a)

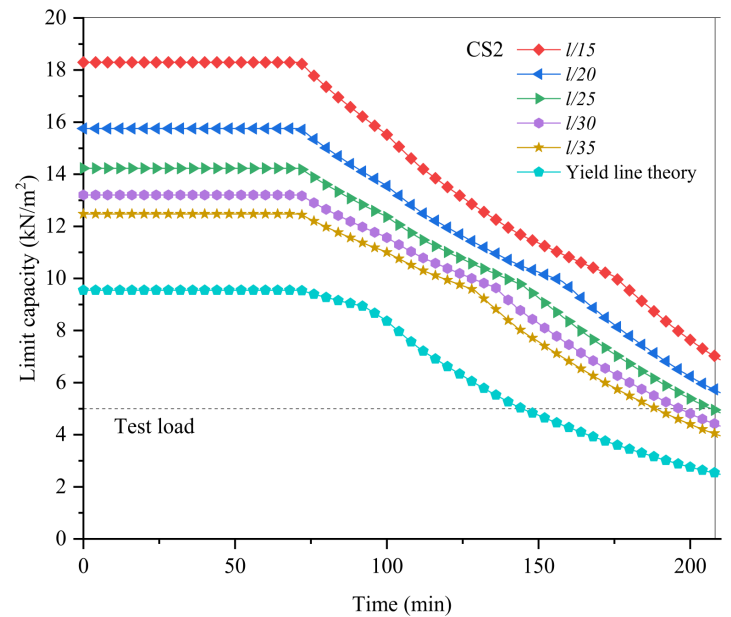

(b)

Figure 29. The ultimate bearing capacity of slab varies with vertical deflections (plate balance method). (a) Slab CS1. (b) Slab CS2.

\section{Discussion}

(1) In the fire test, the method of equivalent bending moment is used to simulate the fixed edge of the test plate, which has a certain deviation from the actual project and will lead to a certain error in the results.

(2) When the steel bar is not perpendicular to the yield line, the work performed by moment rotation and steel bar extension can be determined by projecting the work performed to the yield line after calculating the rotation angle at the yield line.

(3) When calculating the carrying capacity of two-way slab according to Equations (12)-(15) and (31)-(35), the plastic hinge line mode of the slab shall be calculated according to the axis size, reinforcement, and boundary conditions of slab, so as to determine whether the formula is used.

(4) Although in the same fire site, there are still great differences in the temperature of reinforcement at the bottom of the slab at different positions. In the calculation of limit bearing capacity of a two-way slab, according to the physical meaning represented by various parameters and different positions, the measured values of reinforcement at the bottom of the slab at different measuring points are selected as the corresponding temperature in the calculation process.

\section{Conclusions}

Based on the experimental study on the fire resistance of full-scale two-way reinforced concrete slabs with three simply supported edges and one clamped edge, the following conclusions are drawn:

(1) Under the action of fire, the cracks on the top of the two-way reinforced concrete slab with three sides simply supported and one side clamped form a failure mode is shaped similar to the bottom of a shallow bowl. The maximum out-of-plane deflections of the slab occur at the side of the slab center, leaning towards the long simply supported side. The stress redistribution on the clamped side of the slab is obvious, and the concrete temperature field presents a nonlinear distribution along the thickness of the slab. 
(2) The failure mode of the two-way slab with three simply supported edges and one clamped edge under fire exposure is similar to that obtained by conventional yield hinge line theory.

(3) The acceleration change of the two-way slab under fire exposure can be divided into three stages, namely, the stable stage, intense stage, and stable stage.

(4) The change in the vertical first-order frequency of the two-way slab under fire exposure can also be divided into three stages. In the first stage, the change rate of the frequency is the largest, and in the third stage, the change rate of the frequency is the smallest. The vertical first-order frequency of the two-way slab under fire exposure is consistent with the vertical mid-span deflections. Fitting analysis can be used to establish the first-order frequency and the vertical mid-span deflections.

(5) Based on the plate balance method and energy method of yield hinge line, this paper gives the formula for calculating the limit load-carrying capacity of two-way slabs with three simply supported edges and one clamped edge. The calculated results are in good agreement with the experimental results. The traditional yield hinge line theoretical formula is conservative because it does not consider the membrane effect.

Author Contributions: Conceptualization, Y.D.; data curation, S.Z. and S.Y.; funding acquisition, Y.D.; investigation, S.Z., S.Y. and J.D.; methodology, S.Z., D.Z. and J.D.; project administration, S.Z. and S.Y.; supervision, Y.D. and D.Z.; validation, S.Z.; writing-original draft, S.Z.; writing-review and editing, D.Z. All authors have read and agreed to the published version of the manuscript.

Funding: This research was funded by [the National Natural Science Foundation of China] grant number [51778250 and 51978293] and the APC was funded by the authors of this manuscript.

Institutional Review Board Statement: Not applicable.

Informed Consent Statement: Informed consent was obtained from all subjects involved in the study.

Data Availability Statement: The data that support the finding of this study are available from the corresponding author upon reasonable request.

Acknowledgments: This work was supported by the National Natural Science Foundation of China (Grant No. 51778250 and Grant No. 51978293).

Conflicts of Interest: The authors declare no conflict of interest.

\section{References}

1. Selvaggio, S.L.; Carlson, C.C. Effect of Restraint on Fire Resistance of Prestressed Concrete; STP 344, Reprinted as PCA Research Department Bulletin 164; American Society for Testing and Materials: West Conshohocken, PA, USA, 1963; pp. 1-25. [CrossRef]

2. Issen, L.A.; Gustaferro, A.H.; Carlson, C.C. Fire Tests of Concrete Members: An Improved Method for Estimating Thermal Restraint Forces. Fire Test Performance; ASTM: West Conshohocken, PA, USA, 1970; pp. 153-185. [CrossRef]

3. Vecchio, F.J.; Tang, K. Membrane action in reinforced concrete slabs. Can. J. Civ. Eng. 1990, 17, 686-697. [CrossRef]

4. Wade, C.; Lim, L. Experimental Fire Tests of Two-Way Concrete Slabs; Fire Engineering Research Report 02/12; UC Research Repository: Porirua City, New Zealand, 2002; pp. 5-60.

5. Lim, L.; Buchanan, A.; Moss, P. Numerical modeling of two-way reinforced concrete slabs in fire. Eng. Struct. 2004, 26, 1081-1091. [CrossRef]

6. Bailey, C.G.; Toh, W.S. Small-scale concrete slab tests at ambient and elevated temperatures. Eng. Struct. 2007, 29, 2775-2791. [CrossRef]

7. Bailey, C.G.; Toh, W.S. Behaviour of concrete floor slabs at ambient and elevated temperatures. Fire Saf. J. 2007, 42, 425-436. [CrossRef]

8. Wang, B.; Dong, Y.L. Experimental study of two-way reinforced concrete slabs under fire. China Civ. Eng. 2010, 43, 53-62. (In Chinese)

9. Dong, Y.L.; Zhu, C.J. Limit load carrying capacity of two-way slabs with two edges clamped and two edges simply supported in fire. Eng. Struct. 2011, 137, 1182-1192. [CrossRef]

10. Yang, Z.N.; Dong, Y.L. Experimental stydy of two-way reinforced concrete slab subjected to fire in a steel-framed building. Eng. Mech. 2013, 30, 337-344. [CrossRef]

11. Wang, Y.; Dong, Y.L.; Peng, P.W.; Li, S.S. Fire test on floor of full-scale steel-framed structure. J. Build. Struct. 2013, $34,1-11$. [CrossRef] 
12. Li, B.; Dong, Y.-L.; Lou, Y.J.; Wan, L. A fire test of continuous panels in a full-scale steel-framed structure. Eng. Mech. 2015, 32, 145-153.

13. Wang, Y.; Yuan, G.; Huang, Z.; Lyv, J.; Li, Z.-Q.; Wang, T.-y. Experimental study on the fire behaviour of reinforced concrete slabs under combined in-plane and out-of-plane loads. Eng. Struct. 2016, 128, 316-332. [CrossRef]

14. Wang, Y.; Bisby, L.A.; Wang, T.Y.; Yuan, G.; Baharudin, E. Fire behaviour of reinforced concrete slabs under combined biaxial in-plane and out-of-plane loads. Fire Saf. J. 2018, 96, 27-45. [CrossRef]

15. Wang, Y.; Wu, J.-C.; Li, L.-Z.; Zhang, Y.-J.; Chen, Z.-X.; Song, W.; Zhang, X.-Y. Behavior of reinforced concrete continuous two-way slabs subjected to different span fires. Eng. Mech. 2020, 37, 55-72. [CrossRef]

16. Wang, Y.; Zhang, Y.-J.; Long, B.-Y.; Ma, S.; Zhang, S.-H.; Yuan, G.-L. Analytical method for ultimate state of two-way concrete slabs based on steel strain difference. Eng. Mech. 2019, 36, 104-118. [CrossRef]

17. Wang, Y.; Wang, G.; Huang, Z.; Li, L.; Bu, Y.; Zhong, B.; Zhang, Y.; Ma, S. Numerical modelling of in-plane restrained concrete two-way slabs subjected to fires. Fire Saf. J. 2021, 121, 103307. [CrossRef]

18. Dong, Y.L. Calculation of tensile membrane effects of concrete slabs using deformation additive decomposition theorem. Chin. J. Theor. Appl. Mech. 2010, 42, 1180-1187. (In Chinese) [CrossRef]

19. Dong, Y.L. Tensile membrane effects of concrete slabs in fire. Mag. Concr. Res. 2010, 62, 497-505. [CrossRef]

20. Yang, Z.N. Research on Fire Resistance of Two-Way Reinforced Concrete Slabs with Different Edge Restraints; Harbin Institute of Technology: Harbin, China, 2012. (In Chinese) [CrossRef]

21. Zhu, C.J. Studies on Fire Resistance Properties of Full-Sacle Two-Way Reinforced Concrete Slabs; Harbin Institute of Technology: Harbin, China, 2012. (In Chinese) [CrossRef]

22. Zhu, C.J.; Dong, Y.L. An energy method for calculation the load-carrying capacity of two-way slabs with two edges simply supported and two edges clamped in fire. Eng. Mech. 2018, 35, 67-78. (In Chinese) [CrossRef]

23. Zhang, D.; Dong, Y.-L.; Fang, Y.-y. Modification of segment equilibrium method through considering tensile membrane effects and its application in two-way concrete slabs. Eng. Mech. 2017, 34, 201-210. (In Chinese) [CrossRef]

24. Zhang, D.S. Calculation Model for Tensile Membrane Effects of Reinforced Concrete Slabs at Ambient and Elevated Temperature; Harbin Institute of Technology: Harbin, China, 2012. (In Chinese) [CrossRef]

25. Gillie, M.; Usmani, A.S.; Rotter, J.M. A structural analysis of the first Cardington test. J. Constr. Steel Res. 2001, 57, 581-601. [CrossRef]

26. Florides, M.M.; Cashell, K.A. Numerical Modelling of Composite Floor Slabs Subject to Large Deflections. Structures 2016, 9 , 112-122. [CrossRef]

27. Gillie, M.; Usmani, A.; Rotter, M. Bending and membrane action in concrete slabs. Fire Mater. 2004, 28, 139-157. [CrossRef]

28. Franssen, J.M. SAFIR: A thermal/structural program for modelling structures in fire. Eng. J. 2005, 42, 143-158. [CrossRef]

29. Izzuddin, B.A.; Elghazouli, A.Y. Failure of Lightly Reinforced Concrete Members under Fire.I: Analytical Modeling. J. Struct. Eng. 2004, 130, 3-17. [CrossRef]

30. Huang, Z.; Plank, R.J.; Burgess, I.W. Modeling Membrane Action of Concrete Slabs in Composite Buildings in Fire. I: Theoretical Development. J. Struct. Eng. 2003, 129, 1093-1102. [CrossRef]

31. Huang, Z.; Burgess, I.W.; Plank, R.J. Modeling Membrane Action of Concrete Slabs in Composite Buildings in Fire. II: Validations. J. Sturctural Eng. 2003, 129, 1103-1112. Available online: https://ur.booksc.eu/book/40282595/a9bee8 (accessed on 5 December 2021). [CrossRef]

32. GB50010-2010; Code for Design of Concrete Structures of China. China Architecture \& Building Press: Beijing, China, 2011.

33. GB/T 50152-2012; Standard for Test Methods of Concrete Structures. China Architecture \& Building Press: Beijing, China, 2012.

34. GB50009-2012; Load Code for the Design of Building Structures. China Architecture \& Building Press: Beijing, China, 2012.

35. Maraveas, C.; Vrakas, A.A. Design of Concrete Tunnel Linings for Fire Safety. Struct. Eng. Int. 2014, 24, 319-329. [CrossRef]

36. Bailey, C.G.; Khoury, G.A. Performance of Concrete Structures in Fire; The Concrete Centre: Camberley, UK, 2011.

37. International Federation for Structural Concrete (FIB). Fire Design of Concrete Structures—Materials, Structures and Modelling; Bulletin 38; FIB: Lausanne, Switzerland, 2007.

38. Khoury, G.A.; Ander berg, Y. Concrete Spalling Review; Report submitted to the Swedish National Road Administration; Swedish National Road Administration: Borlänge, Sweden, 2000.

39. Hertz, K.D. Limits of spalling of fire-exposed concrete. Fire Saf. J. 2003, 38, 103-116. [CrossRef]

40. Ye, S.G. Study on Performance of Long-to-Edge Fixed-Supported Short-to-Edge Simple-Supported Bidirectional Board under Fire; Huaqiao University: Quanzhou, China, 2019. (In Chinese)

41. Li, S. Study on Fire Performance of Two-way Concrete Slabs Supported Simply on Three Sides and Fixedly on One Side; Huaqiao University: Quanzhou, China, 2020. (In Chinese) [CrossRef]

42. Zhu, S.F.; Dong, Y.L.; Duan, J.T. Fire behavior research of rectangular reinforced concrete two-way slabs simply supported on two long sides and fixed on two short sides. J. Huaqiao Univ. Nat. Sci. 2021. [CrossRef]

43. ISO834; Fire Resistance Tests-Elements of Building Construction. ISO: Geneva, Switzerland, 1980.

44. ASTM E119; ASTM Standard Methods of Fire Test of Building Construction and Materials; Test Method. American Society for Testing and Materials: West Conshohocken, PA, USA, 2001.

45. Kodur, V.K.R.; Dwaikat, M. A numerical model for predicting the fire resistance of reinforced concrete beams. Cem. Concr. Compos. 2008, 30, 431-443. [CrossRef] 
46. Bailey, C.G. Membrane action of unrestrained lightly reinforced concrete slabs at large displacements. Eng. Struct. 2001, 23, 470-483. [CrossRef]

47. EN 1992-1-2; Eurocode 2: Design of Concrete Structures-Part 1.2: General Rules—Structural Fire Design. British Standards Instituion: London, UK, 2004.

48. Wang, Y.; Dong, Y.L.; Zou, C.Y. Calculation of limit carrying capacity of reinforced concrete slabs. J. Harbin Inst. Technol. 2013, 45, 8-13. (In Chinese) [CrossRef]

49. Wang, Y.; Dong, Y.L.; Zou, C.Y. Comparative analysis of limit carrying capacity of reinforced concrete slabs. J. Harbin Inst. Technol. 2013, 45, 1-7. (In Chinese) [CrossRef]

50. Zhu, S.-F.; Dong, Y.-L.; Zhang, D.-S.; Duan, J.-T. Calculation of ultimate bearing capacity of four different boundary two-way slabs under fire. Eng. Mech. 2022, 3, 104-114. 